University of New Orleans

ScholarWorks@UNO

$6-2008$

\title{
Three-dimensional seismic array characterization study: Experiment and modeling
}

Arslan M. Tashmukhambetov

University of New Orleans

George E. loup

University of New Orleans

Juliette W. Ioup

University of New Orleans

Natalia A. Sidorovskaia

Joal J. Newcomb

Follow this and additional works at: https://scholarworks.uno.edu/phys_facpubs

Part of the Physics Commons

\section{Recommended Citation}

J. Acoust. Soc. Am. 123 (6), 4094 (2008)

This Article is brought to you for free and open access by the Department of Physics at ScholarWorks@UNO. It has been accepted for inclusion in Physics Faculty Publications by an authorized administrator of ScholarWorks@UNO.

For more information, please contact scholarworks@uno.edu. 


\title{
Three-dimensional seismic array characterization study: Experiment and modeling ${ }^{\text {a) }}$
}

\author{
Arslan M. Tashmukhambetov, George E. loup, and Juliette W. loup \\ Department of Physics, University of New Orleans, New Orleans, Louisiana 70148 \\ Natalia A. Sidorovskaia ${ }^{\text {) }}$ \\ Department of Physics, University of Louisiana at Lafayette, P.O. Box 44210, \\ Lafayette, Louisiana 70504-4210 \\ Joal J. Newcomb \\ Naval Research Laboratory-Stennis Space Center, Mississippi 39529
}

(Received 22 August 2007; revised 20 February 2008; accepted 5 March 2008)

In the summer of 2003, the Littoral Acoustic Demonstration Center conducted an acoustic characterization experiment for a 21-element marine seismic exploration airgun array of total volume of $0.0588 \mathrm{~m}^{3}$ (3590 in. ${ }^{3}$ ). Two Environmental Acoustic Recording System buoys, one with a desensitized hydrophone, were deployed at a depth of $758 \mathrm{~m}$ in a water depth of $990 \mathrm{~m}$, near Green's Canyon in the Gulf of Mexico. Shots over a grid were recorded and calibrated to produce absolute broadband (up to $25 \mathrm{kHz}$ ) pressure-time dependencies for a wide range of offsets and arrival angles in the water column. Experimental data are analyzed to obtain maximum received zero-to-peak pressure levels, maximum received sound exposure levels, and pressure levels in $1 / 3$-octave frequency bands for each shot. Experimental data are quantitatively modeled by using an upgraded version of an underwater acoustic propagation model and seismic source modeling packages for a variety of ranges and arrival angles. Experimental and modeled data show good agreement in absolute pressure amplitudes and frequency interference patterns for frequencies up to $1000 \mathrm{~Hz}$. The analysis is important for investigating the potential impact on marine mammals and fish and predicting the exposure levels for newly planned seismic surveys in other geographic areas. (C) 2008 Acoustical Society of America. [DOI: 10.1121/1.2902185]

PACS number(s): 43.30.Dr, 43.30.Zk, 43.80.Nd, 43.20.Mv [JAS] Pages: 4094-4108

\section{INTRODUCTION}

In the past decade, a considerable amount of effort has been focused on understanding how sound generated by human-made acoustic sources in the ocean may influence marine mammals. One of the important aspects of this effort is the measurement and prediction of the broadband acoustic energy distribution of such sources in complex variable ocean waveguides. Seismic exploration arrays are of interest for environmental impact assessment (Gordon et al., 2004). These arrays comprise a collection of airguns distributed over an array geometry and towed behind a seismic vessel. They are designed to fire synchronously and produce powerful highly directional bottom-directed pulses to image acoustically the sub-bottom structure. The geophysical response is primarily analyzed in the low frequency band up to $300 \mathrm{~Hz}$ (Caldwell and Dragoset, 2000). Hence, the higher frequency component of acoustic radiation from a seismic array has been mostly overlooked until concerns were raised about the

\footnotetext{
a) Portions of this work were presented in "Calibration and Analysis of Seismic Airgun Data from an EARS Buoy," Proceedings of 23rd Annual Gulf of Mexico Information Transfer Meeting, New Orleans, Louisiana, January 2005; "Modeling tools for 3-d airgun characterization studies," Proceedings of the Eighth ECUA, Carvoeiro, Portugal, June 2006; "3-D airgun source characterization and propagation modeling," SEG Technical Program Expanded Abstracts, New Orleans, Louisiana, October 2006.

${ }^{b)}$ Electronic mail: nas@louisiana.edu
}

effect of this radiation on marine species, especially marine mammals, that rely on acoustics as a survival tool (for orientation, food foraging, communication, etc.). Recent studies of individual sperm whale communication codas strongly suggest that frequencies above $1000 \mathrm{~Hz}$ are of particular importance in sperm whale communication (Ioup et al., 2005). This frequency range may overlap with the high frequency component of seismic array radiation. On-whale tag recordings during controlled exposure experiments conducted in the Northern Gulf of Mexico (GoM) in 2002 and 2003 showed that received peak pressures and sound exposure levels (SEL's) of tagged whales do not necessarily decrease as the range between the whale and the seismic array increases under certain circumstances, such as constructive interference of overlapping arrivals, the presence of a surface duct, etc. (Madsen et al., 2006). Reported data show that absolute received pressure levels can be as high at $12 \mathrm{~km}$ as they are at $2 \mathrm{~km}$. It strongly suggests that spherical and cylindrical spreading approaches should not be automatically used to determine impact zones and that animal SEL should be determined from existing waveguide propagation conditions and three-dimensional source array directional patterns.

There are discussions in the underwater acoustic community and oil industry about the results of quantitative studies of the effects of waveguide propagation including surface ducts, which are formed seasonally in the GoM, on acoustic 

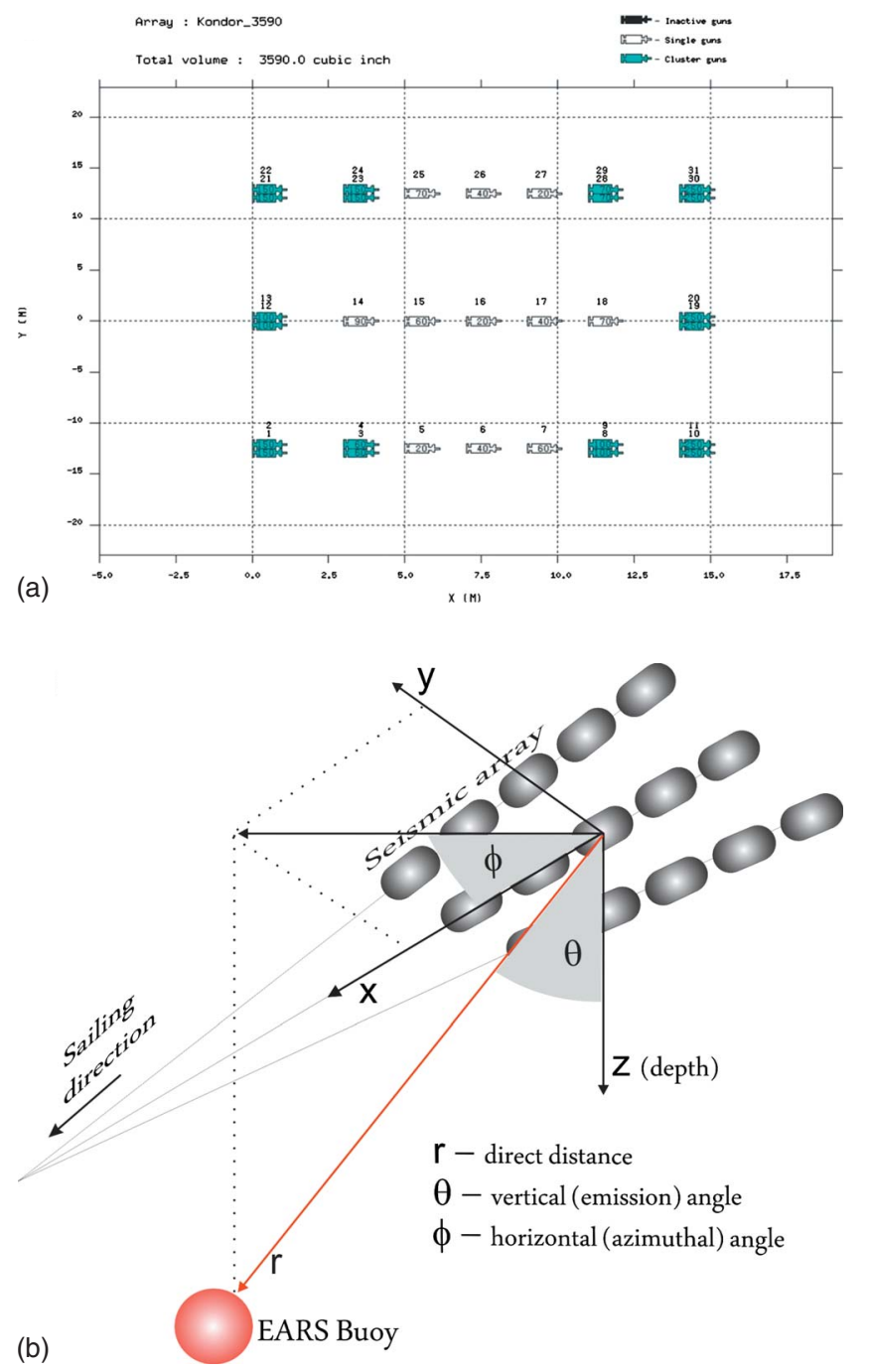

FIG. 1. (Color online) (a) The M/V Kondor seismic array configuration for the seismic characterization experiment. The numbers inside each airgun indicate the individual volume in in. ${ }^{3}$ of each airgun. (b) Reference coordinate system with the origin at the array center.

energy distribution (MacGillivray, 2006; DeRuiter et al., 2006; Tolstoy et al., 2004). Surface ducts can form a series of energetically powerful precursor pulses (arriving before the main energy associated with the direct arrival) spread throughout the entire depth of the water column with a range decay rate slower than that of the direct arrival (Labianca, 1972; Monjo and DeFerrari, 1994; Sidorovskaia and Werby, 1995; Sidorovskaia, 2004). Therefore, an animal at any depth can be exposed to significant levels of acoustic energy that are not associated with the direct arrival. Hence, waveguide propagation modeling should become an indispensable part of the development of any mitigation metrics. Both calibrated measurements and quantitative modeling of a seismic array energy distribution for a full range of angles and emitted frequencies become the first steps in our ability to predict and mitigate any potentially negative effects.

In the first part of this paper, we present experimental calibrated measurements of the broadband absolute pressure output from an industrial seismic exploration airgun array, which has been collected by the Littoral Acoustic Demonstration Center (LADC) in June 2003 for three-dimensional

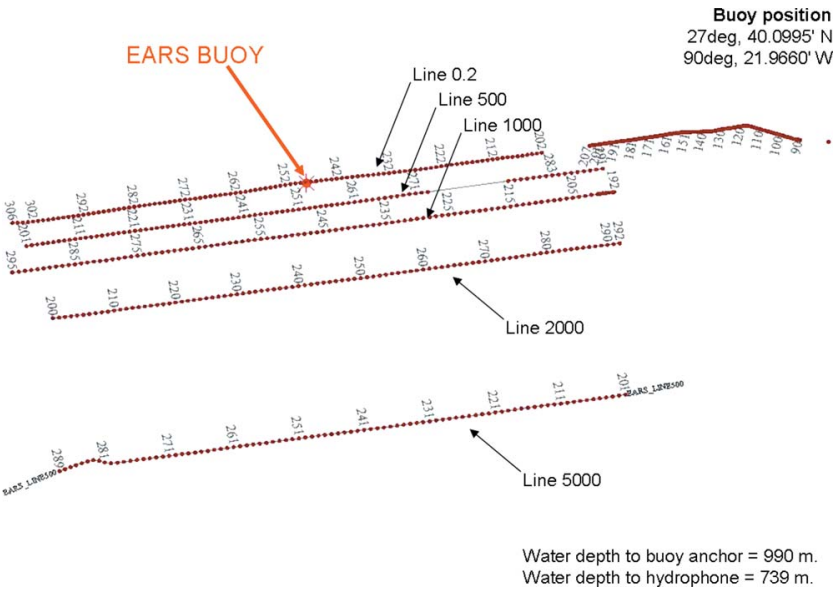

FIG. 2. (Color online) The M/V Kondor line/shot diagram in the horizontal plane. The nominal seismic array depth is $6.7 \mathrm{~m}$ below the surface.

seismic source characterization studies. LADC, which was founded in 2001, currently is a consortium of scientists from three universities (the University of New Orleans, the University of Southern Mississippi, and the University of Louisiana at Lafayette) and the Naval Research Laboratory at Stennis Space Center. Since 2001, LADC has conducted or participated in eight experiments in the Northern GoM and the Mediterranean Sea to study natural and anthropogenic noise in marine environments and the potential impact on marine mammals (Newcomb et al., 2002a, 2002b; Newcomb et al., 2005; Sidorovskaia et al., 2006; Tashmukhambetov et al., 2006). In the second part of the paper, we present the results of quantitative modeling of measured absolute pressures by using enhanced modeling techniques based on the standard underwater acoustic propagation model [the range dependent acoustic model (RAM)].

\section{EXPERIMENT}

\section{A. Source/receiver configuration}

LADC deployed Environmental Acoustic Recording System (EARS) buoys developed by the Naval Oceanographic Office. Two single channel EARS buoys $(25 \mathrm{kHz}$ bandwidth) were colocated on the same mooring near Green's Canyon in the Northern GoM $\left(27^{\circ} 40.0995^{\prime} \mathrm{N}\right.$, $90^{\circ} 21.9660^{\prime} \mathrm{W}$ ) during June 2003 for a seismic characterization experiment. One buoy hydrophone recorded ambient noise and the other was desensitized (by $12.7 \mathrm{dBV}$ ) to record marine seismic array emissions without clipping the data. The hydrophone of each buoy was approximately $250 \mathrm{~m}$ from the bottom in a water depth of about $990 \mathrm{~m}$. Only the data from the desensitized EARS hydrophone are discussed in this paper. The M/V Kondor towed a 21-element seismic airgun array of total volume of $3590 \mathrm{in}^{3}\left(0.0588 \mathrm{~m}^{3}\right)$ on five parallel linear tracks with horizontal closest approach points to the EARS buoy position of $63,500,1000,2000$, and $5000 \mathrm{~m}$. The seismic array configuration is shown in Fig. 1(a). Figure 1(b) shows the reference coordinate system used in the paper to characterize the array directionality. The emission angle $\theta$ is the angle between the vertical and a line connecting the position of the array center and a receiving 


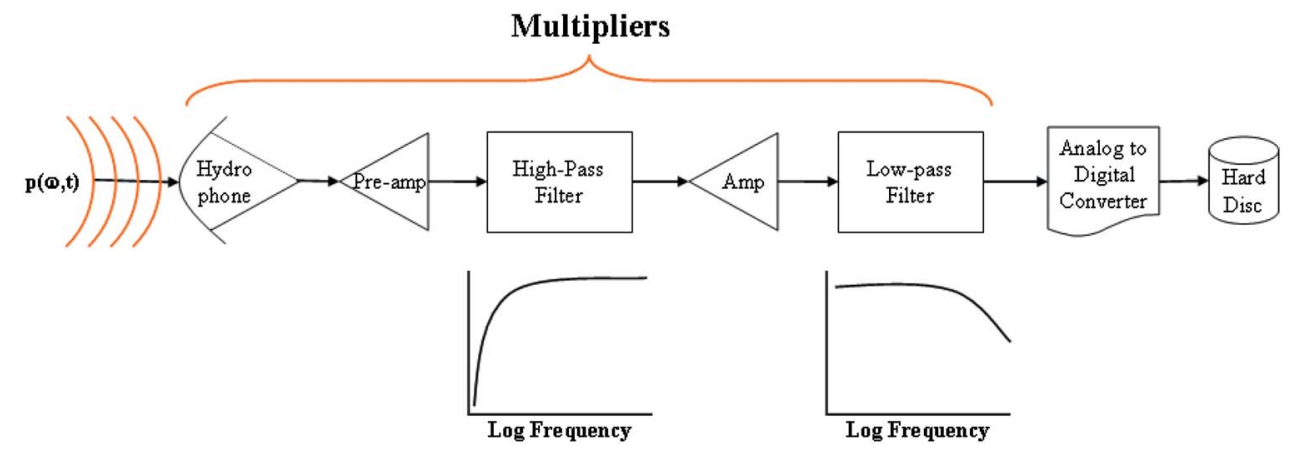

b)
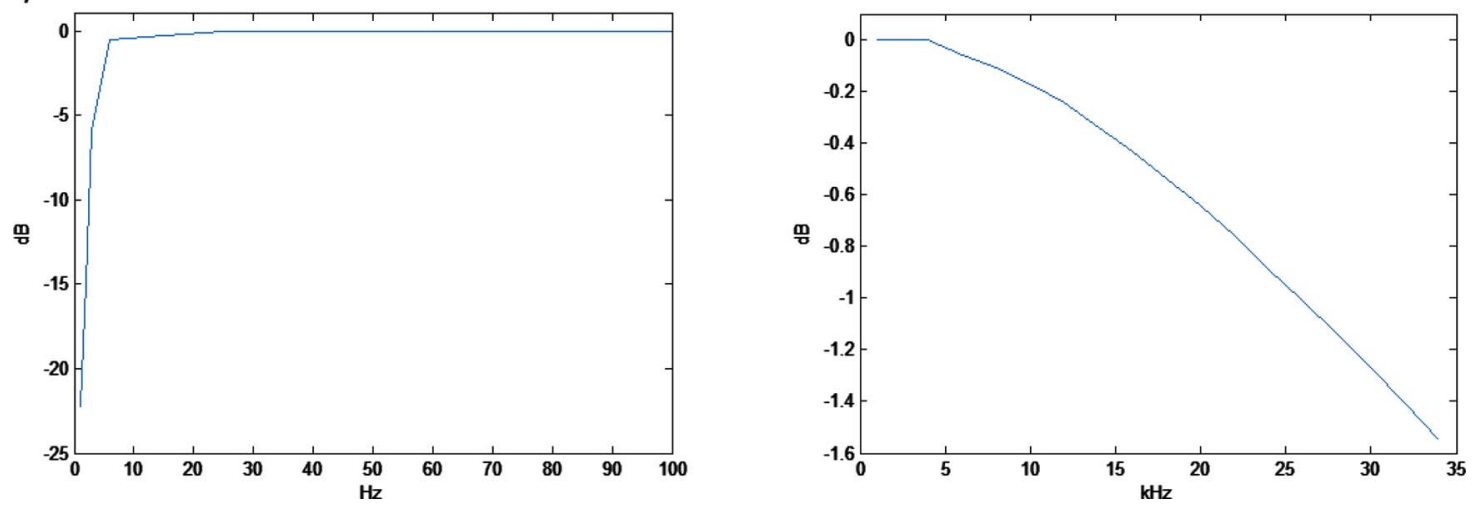

FIG. 3. (Color online) (a) Block diagram illustrating the data flow in a typical acoustic data acquisition system and the components that affect final data calibration. (b) Desensitized hydrophone frequency response curve used for calibration (low- and high-frequency extremes are shown separately for clarity).

hydrophone. The azimuthal angle $\phi$ is measured in the horizontal plane with $0^{\circ}$ directly in front of the array, $180^{\circ} \mathrm{di}$ rectly behind, $90^{\circ}$ to starboard, and $270^{\circ}$ to port. The tracks provide a wide range of measured emission angles $\left(6^{\circ}-84^{\circ}\right.$, with $0^{\circ}$ corresponding to the vertical) and horizontal ranges up to $7 \mathrm{~km}$ from the array center to the EARS buoys. The Kondor tracks (labeled as line 0.2, line 500, line 1000, line 2000, and line 5000) are illustrated in Fig. 2. The total number of shots recorded was about 500 .

\section{B. Experimental data calibration}

In order to obtain absolute measured sound pressure levels, it is important that the recording equipment calibrations be fully understood. Figure 3 is a block diagram of the data acquisition flow in a typical EARS buoy. Two calibration methods have been implemented for the EARS buoys. The first method, which is often called a frequency-domain method since the result is a direct function of frequency, involves injecting a single narrowband sine wave into the electronics downstream of the hydrophone. The input voltage magnitude and phase of the injected signal are compared to the output voltage. This is repeated for many different frequencies to obtain the transfer function of the equipment across a broad frequency band. In the other method, which is often called the time-domain method since the result is a direct function of time, a temporally very short signal (4.7 $\mu \mathrm{s}$ long) is injected into the electronics downstream of the hydrophone. The temporally short characteristic of this "impulse" results in a very wide band of frequencies. The output is recorded and is a direct measure of the impulse response of the equipment. Ideally, the impulse response of the equipment and the transfer function of the equipment are Fourier transform pairs and will lead to the same final results
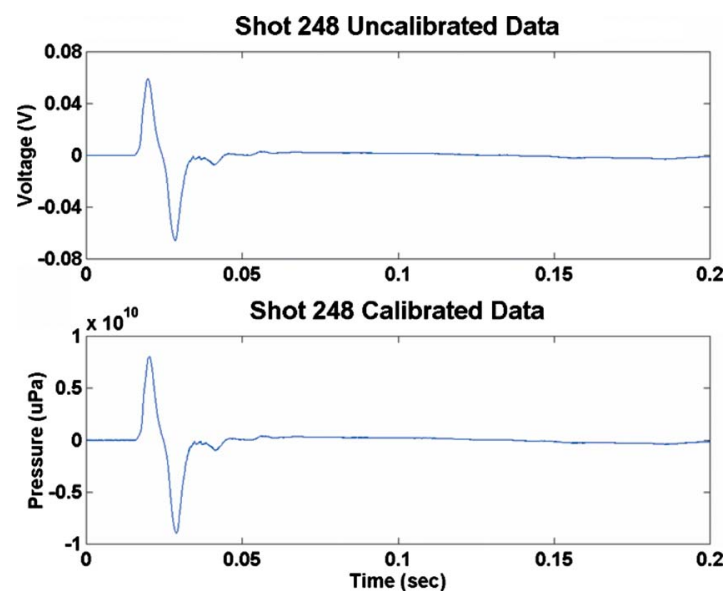

FIG. 4. (Color online) Calibration results for $200 \mathrm{~ms}$ of acoustic data corresponding to the direct arrivals from an airgun shot near the CPA of the array to the EARS buoy. The upper plot shows the raw data in $\mathrm{V}$ and the bottom plot shows the same data segment in $\mu \mathrm{Pa}$ after all the calibrations have been applied. The EARS response (including the hydrophone) is nearly flat from $6 \mathrm{~Hz}$ to $25 \mathrm{kHz}$ so that the two plots have very small differences except in units. 

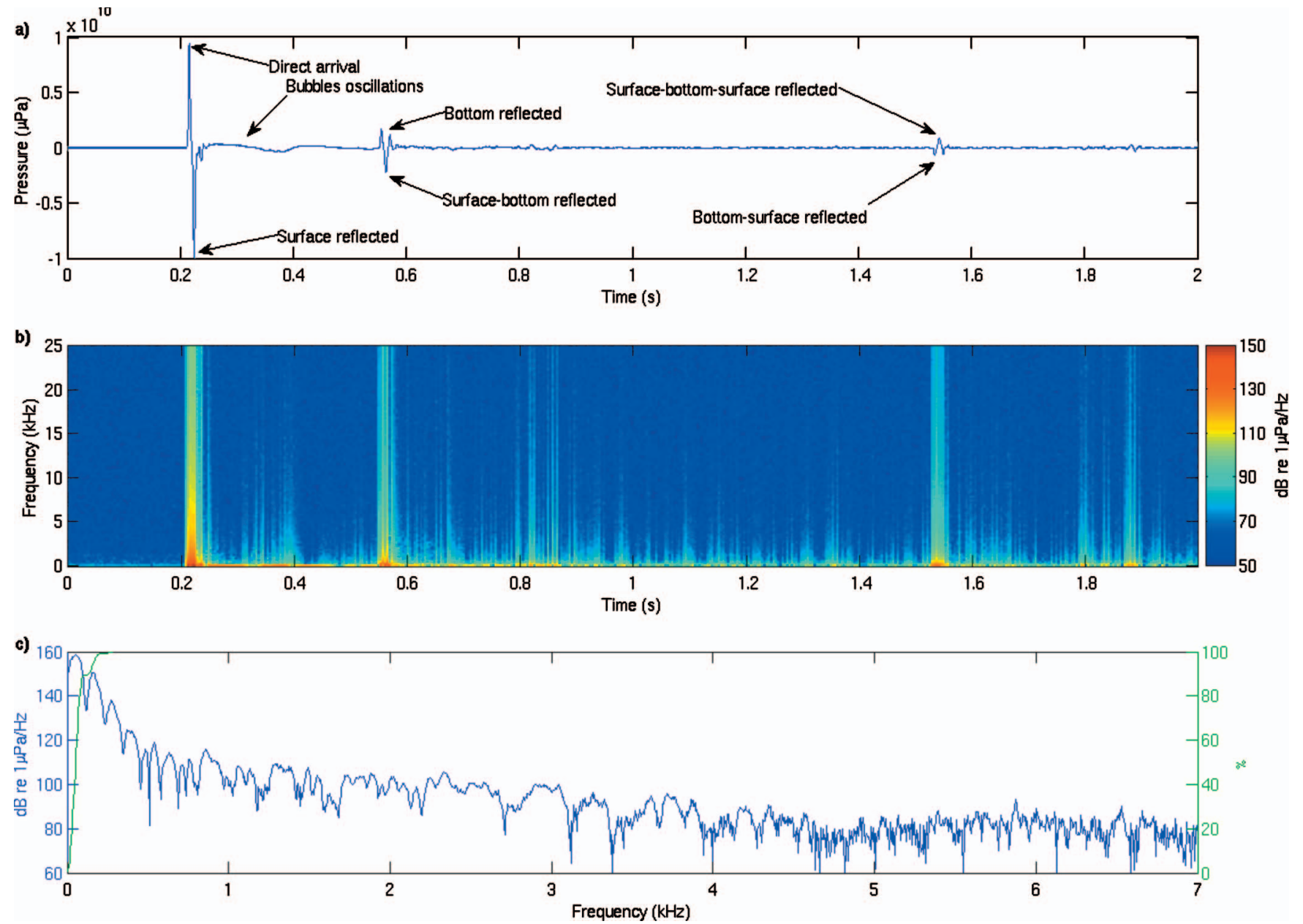

FIG. 5. (a) Measured absolute calibrated acoustic pressure for the CPA shot 249 on line 0.2 vs time. The horizontal range is $63 \mathrm{~m}$, the direct distance to the hydrophone is $736 \mathrm{~m}$, the emission angle is $5^{\circ}$, and the azimuthal angle is $202^{\circ}$. (b) Spectrogram of the signal in (a) using a $5 \mathrm{~ms}$ rectangular window with $20 \%$ overlap from $6 \mathrm{~Hz}$ to $25 \mathrm{kHz}$. (c) The calibrated amplitude spectrum over a $2 \mathrm{~s}$ rectangular window with a start time corresponding to the $0.2 \mathrm{~s}$ temporal mark of the spectrogram in (b) and cumulative energy flux in \% vs frequency.

when appropriately applied to the raw data. For the LADC 2003 experiment, a comparison of the two methods for the desensitized EARS buoy yielded the same results between $6 \mathrm{~Hz}$ and $25 \mathrm{kHz}$. Since the time-domain method requires the use of more complicated deconvolution techniques to remove the impulse response from the recorded data, all final calibrations of the recorded data were performed using the frequency-domain method. It must be noted that neither of the above methods of calibration includes the response of the hydrophone itself. This must be included in the final calibration of the acoustic data to obtain absolute pressure levels. The hydrophone transfer functions have been determined by the manufacturer. Figure 4 illustrates $200 \mathrm{~ms}$ of acoustic data corresponding to the direct arrivals from an array emission near the closest point of approach (CPA) of the array to the EARS buoy. The upper plot is the raw data in volts and the bottom plot is the same data segment in micropascals after all the calibrations have been applied. The EARS response (including the hydrophone) is nearly flat from $6 \mathrm{~Hz}$ to $25 \mathrm{kHz}$ so that the two plots have very little difference except in units. We will restrict our analyses of the data to this calibrated frequency band (6 Hz to $25 \mathrm{kHz})$.

\section{EXPERIMENTAL DATA ANALYSIS: METHODS AND RESULTS}

Seismic arrays are designed to be highly directional in order to focus the low-frequency sound energy in the vertical direction for the purpose of seismic exploration. The probability that a marine mammal will be exposed to the near vertical downward propagating direct pulse is fairly small. This is not so with off-axis acoustic emissions, so studies of off-axis acoustic signatures are of special interest. Hence, multipath propagation and leakage of high-frequency energy from the airgun array into the ocean waveguide are critical issues for studying the impact on marine mammals. Figures 5-7 show a series of absolute acoustic pressures versus time recorded during the experiment and the corresponding spectrograms for individual shots on different tracks with different horizontal ranges from the center of the array to the buoy location and different emission and azimuthal angles. The spectrograms $S\left(f_{k}, t_{m}\right)$ are calculated over a $5 \mathrm{~ms}$ window with $20 \%$ overlap,

$$
S\left(f_{k}, t_{m}\right)=20 \log \{|\sqrt{2} F(k, m)|\}, \quad k=1, \ldots, N / 2-1,
$$



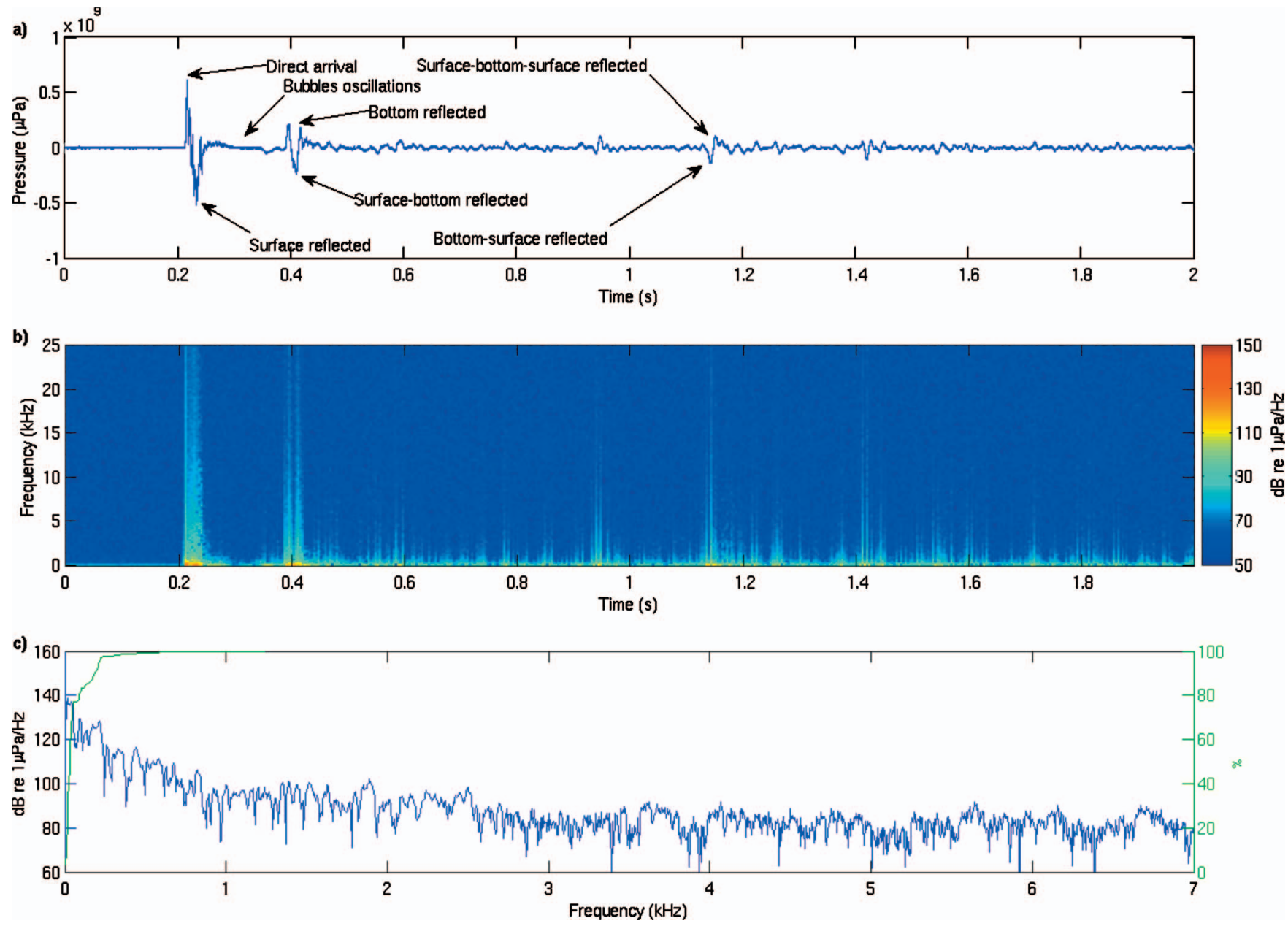

FIG. 6. (a) Measured absolute calibrated acoustic pressure for shot 235 on line 1000 vs time. The horizontal range is $1655 \mathrm{~m}$, the direct distance to the hydrophone is $1810 \mathrm{~m}$, the emission angle is $66^{\circ}$, and the azimuthal angle is $144^{\circ}$. (b) Spectrogram of the signal in (a) over a $5 \mathrm{~ms}$ rectangular window with $20 \%$ overlap from $6 \mathrm{~Hz}$ to $25 \mathrm{kHz}$. (c) The calibrated amplitude spectrum over a $2 \mathrm{~s}$ rectangular window with a start time corresponding to the $0.2 \mathrm{~s}$ temporal mark of the spectrogram in (b) and cumulative energy flux in \% vs frequency.

$$
\begin{gathered}
F(k, m)=\Delta t \sum_{j=0}^{N-1} p\left[\left(j+N_{s} m\right) \Delta t\right] e^{-i 2 \pi j k / N}, \\
k=0,1, \ldots, N-1, \quad m=0, \ldots, M,
\end{gathered}
$$

where $F(k, m)$ are complex Fourier coefficients obtained from a standard fast Fourier transform program; $p(j \Delta t)$ are calibrated temporal pressure samples; $N=390$ is the number of pressure samples in a $5 \mathrm{~ms}$ analysis window; $\Delta t=1.28$ $\times 10^{-5} \mathrm{~s}$ is the sampling interval for the collected data; $f_{k}$ $=\Delta f k, \Delta f=(\Delta t N)^{-1}, k=0,1, \ldots, N / 2 ; N_{s}=N \cdot 0.8$ is the temporal index shift in terms of pressure sample number for $20 \%$ overlap; $M=N_{0} / N_{s}$ is the integer number of spectral windows in a $2 \mathrm{~s}$ spectrogram. The calculation of the Fourier coefficients in Eq. (1) reflects the transient nature of the measured seismic signatures that should be considered finiteenergy signals, not power signals. (Fricke et al., 1985; Johnston et al., 1988). Instead of the power flux spectral density traditionally analyzed for infinitely long stationary signals, an energy flux spectral density $\varepsilon(k)$ is quantified in the calibration procedure for marine seismic source transient signals (Fricke et al., 1985):

$$
\varepsilon(k)=\frac{1}{\rho c}|F(k)|^{2},
$$

where $F(k)$ is the discrete Fourier transform coefficient, which is defined in Eq. (1) for a single $m$ value, $\rho$ is the water density at the receiver position, and $c$ is the speed of sound at the measuring point. The energy flux spectral density curve has the same shape as the amplitude spectrum (absolute values of the Fourier coefficients) but different units $\left(\mathrm{J} /\left(\mathrm{m}^{2} \mathrm{~Hz}\right)\right)$. For a decibel scale, the amplitude spectrum level (referenced to $1 \mu \mathrm{Pa}$ ) is $182 \mathrm{~dB}$ larger than the energy flux spectral density level (referenced to $1\left(\mathrm{~J} /\left(\mathrm{m}^{2} \mathrm{~Hz}\right)\right)$ if the acoustic impedance of sea water is approximated by the constant value

$$
Z=\rho c=1026 \frac{\mathrm{kg}}{\mathrm{m}^{3}} \times 1500 \frac{\mathrm{m}}{\mathrm{s}} \approx 1.54 \times 10^{6} \mathrm{~Pa} \mathrm{~s} / \mathrm{m} .
$$

Following SEG standards for specifying marine seismic energy sources (Johnston et al., 1988), cumulative energy flux $u(k)$ and total energy flux $u(N / 2)$ are calculated for the experimental data, 

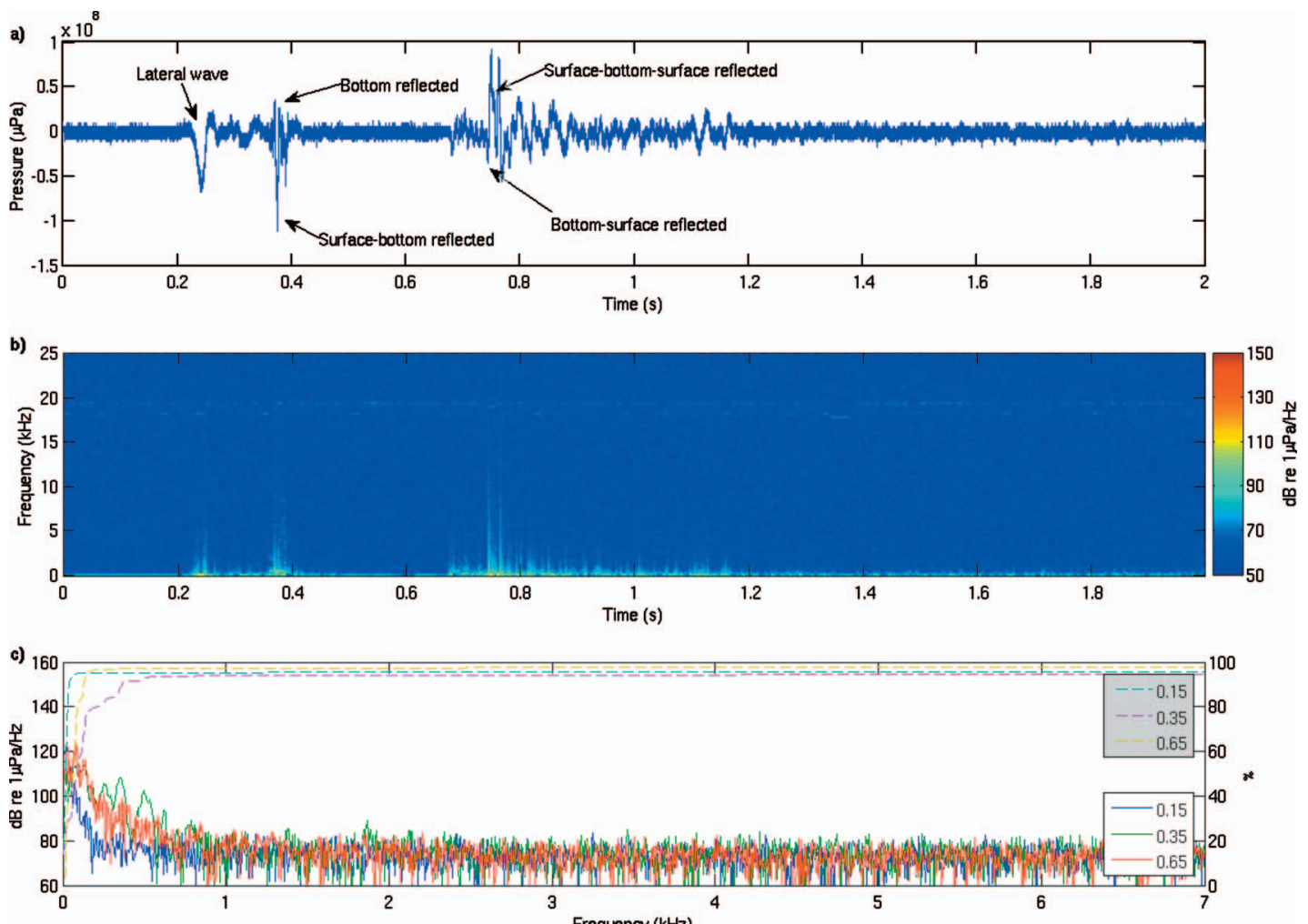

aj

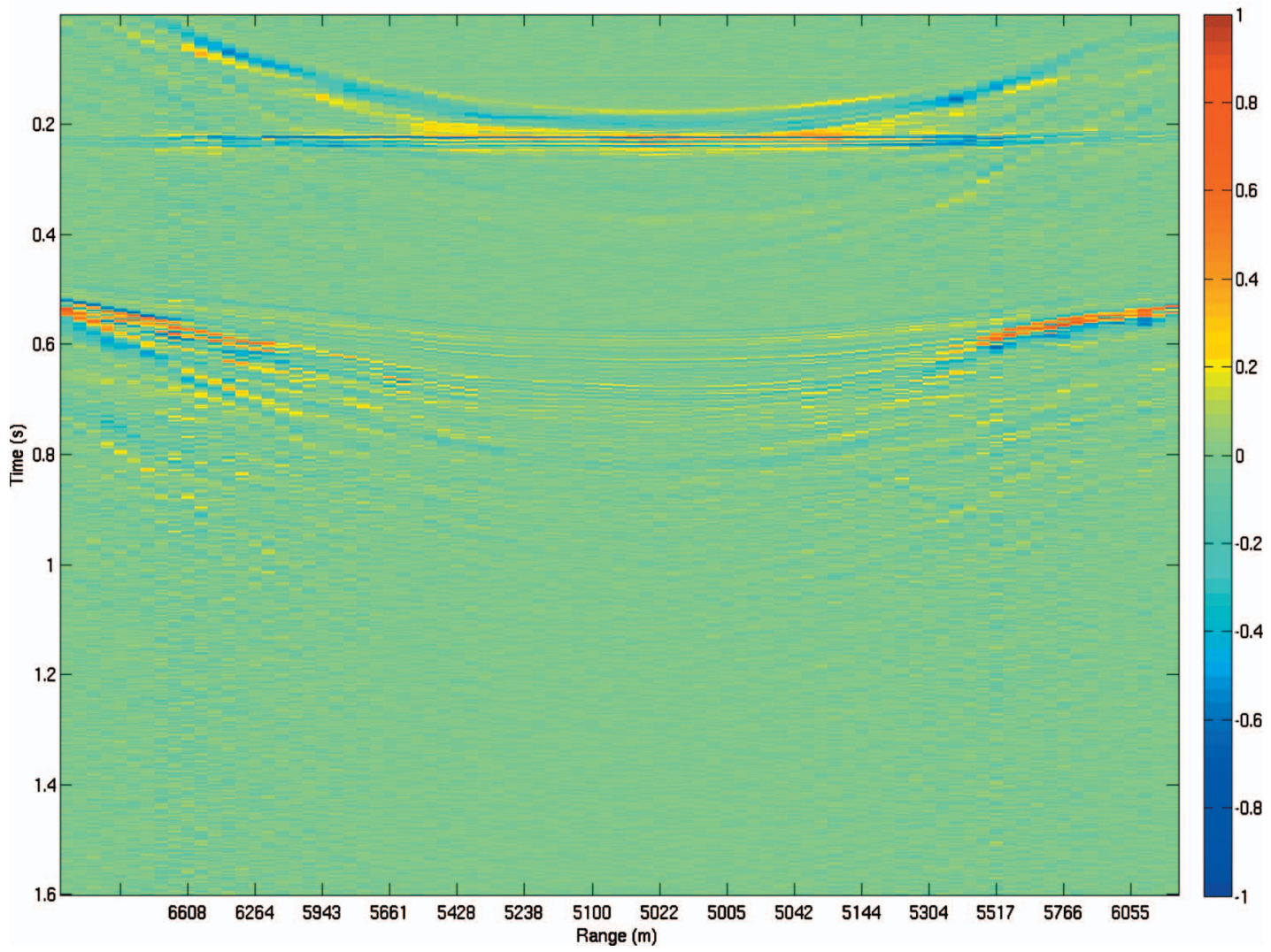

FIG. 7. (a) Measured absolute calibrated acoustic pressure for shot 211 on line 5000 vs time. The horizontal range is $6197 \mathrm{~m}$, the direct distance to the hydrophone is $6240 \mathrm{~m}$, the emission angle is $83^{\circ}$, and the azimuthal angle is $128^{\circ}$. (b) Spectrogram of the signal in (a) over a $5 \mathrm{~ms}$ rectangular window with $20 \%$ overlap from $6 \mathrm{~Hz}$ to $25 \mathrm{kHz}$. The lateral (head) wave precursor is the first arrival. High frequencies are attenuated as would be expected for a lateral wave. (c) The calibrated amplitude spectra over a $0.2 \mathrm{~s}$ rectangular window with start times corresponding to the $0.15,0.35$, and $0.65 \mathrm{~s}$ temporal marks of the spectrogram in (b) and cumulative energy fluxes (\%) vs frequency. (d) Normalized signal moveout map for line 5000 shots. The time is synchronized on the first bottom reflection. Each shot pressure function is normalized by the absolute value of the maximum pressure in this shot. The separation between a precursor and a reference (strongest) arrival increases with range. 


$$
\begin{aligned}
& u(k)=\Delta f \varepsilon(0)+2 \Delta f \sum_{l=1}^{k} \varepsilon(l), \quad k=1, \ldots, N / 2-1, \\
& u(0)=\Delta f \varepsilon(0), \quad u(N / 2)=u(N / 2-1)+\Delta f \varepsilon(N / 2) .
\end{aligned}
$$

The cumulative energy flux corresponds to the amount of energy flux in a frequency band from $0 \mathrm{~Hz}$ to $k \Delta f$. The total energy flux is the cumulative energy flux in the full recorded frequency band. The cumulative energy flux is usually expressed as a percentage of the total energy flux,

$$
\widetilde{u}(k)=\frac{u(k)}{u(N / 2)} \times 100 \%, \quad k=0,1, \ldots, N / 2 .
$$

Figure 5(a) shows the measured calibrated pressure in micropascals for the closest approach point on line 0.2, which corresponds to a horizontal range of $63 \mathrm{~m}$, with a direct distance to the hydrophone of $736 \mathrm{~m}$, emission angle of $5^{\circ}$, and azimuthal angle of $202^{\circ}$. The $2 \mathrm{~s}$ shot spectrogram is shown in Fig. 5(b). The amplitude spectrum level and cumulative energy flux for the $200 \mathrm{~ms}$ Fourier analysis window with a start time corresponding to the $0.2 \mathrm{~s}$ mark on the spectrogram plot are in Fig. 5(c). The direct arrival, surface reflected arrival, bottom reflected arrival, bubble oscillation cycle, and multiples can be clearly identified in Figs. 5(a) and 5(b). The separation between the direct and bottom reflected arrivals is $340 \mathrm{~ms}$. The maximum amplitude spectrum power level is $159 \mathrm{~dB}$ re $1 \mu \mathrm{Pa} / \mathrm{Hz}$, with the level reaching $110 \mathrm{~dB}$ re $1 \mu \mathrm{Pa} / \mathrm{Hz}$ at $1000 \mathrm{~Hz}$ for the direct arrival and $85 \mathrm{~dB}$ re $1 \mu \mathrm{Pa} / \mathrm{Hz}$ at $5000 \mathrm{~Hz}$ for the direct arrival. The calculated total energy flux is $0.32 \mathrm{~J} / \mathrm{m}^{2}$. The sound propagation geometry to the EARS buoy for this shot is nearly vertical for the direct and bottom reflected pulses. The seismic arrays are tuned for optimal (near vertical) transmission of low frequencies for this geometry. The cumulative energy flux plot in Fig. 5(c) shows that most of the energy is under $300 \mathrm{~Hz}$. This is consistent with the array design. The high frequencies are about $35 \mathrm{~dB}$ lower than the $300 \mathrm{~Hz}$ level. Semiquantitative comparison from Fig. 5(b) shows that the direct path signal energy flux spectral density level is about $20 \mathrm{~dB}$ greater at most high frequencies than the bottom reflected arrival and the multiples.

Figures 6(a)-6(c) show similar plots for shot 235 on line 1000. The horizontal range is $1655 \mathrm{~m}$, the direct distance to the hydrophone is $1810 \mathrm{~m}$, the emission angle is $66^{\circ}$, and the azimuthal angle is $144^{\circ}$. The calculated total energy flux is $0.0017 \mathrm{~J} / \mathrm{m}^{2}$. The arrival structure is still identifiable and labeled in Figs. 6(a) and 6(b). The separation between the direct and bottom reflected arrivals is decreased to $200 \mathrm{~ms}$. This may potentially indicate an increased sound exposure level vs range to the shot for an animal having a $200 \mathrm{~ms}$ energy integration window (as discussed below). The maximum amplitude spectrum power level is $125 \mathrm{~dB}$ re $1 \mu \mathrm{Pa} / \mathrm{Hz}$, with the level reaching $100 \mathrm{~dB}$ re $1 \mu \mathrm{Pa} / \mathrm{Hz}$ at $1000 \mathrm{~Hz}$ for the direct arrival and $80 \mathrm{~dB}$ re $1 \mu \mathrm{Pa} / \mathrm{Hz}$ at $5000 \mathrm{~Hz}$ for the direct arrival, which is close to the background noise level. Figure 6(c) shows again that most of the energy is at a low frequency, under $500 \mathrm{~Hz}$. At this range, the difference is about $25 \mathrm{~dB}$ between the high frequency and the $500 \mathrm{~Hz}$ levels.

Figures 7(a)-7(c) present the data for shot 211 on line 5000. The horizontal range is $6197 \mathrm{~m}$, the direct distance to the hydrophone is $6240 \mathrm{~m}$, the emission angle is $83^{\circ}$, and the azimuthal angle is $128^{\circ}$. The signal is more complicated and the interpretation of the arrival pattern is not as straightforward as for the shots shown in Figs. 5 and 6. The spectra reveal that most of the energy of the precursor is below $300 \mathrm{~Hz}$. As one can see from the moveout of the signal with different shots on line 5000 in Fig. 7(d), the temporal separation between the precursor and the main energy arrival increases with range. An additional analysis of the signal move-out curves for other lines indicates that the precursor starts appearing at ranges larger than $4.5 \mathrm{~km}$. These features of the precursor arrival strongly suggest that it is a lateral (head, interface) wave. Correlation of experimental time delays between arrivals with modeled ones is required to gain more confidence concerning the analysis of the precursor. The frequency partition of energy for the various components of this shot is similar to that shown in the previous two figures. The amplitude spectrum level and cumulative energy flux for the $200 \mathrm{~ms}$ Fourier analysis window for three identifiable arrivals with start times corresponding to $0.15,0.35$, and $0.65 \mathrm{~s}$ on the spectrogram plot are shown in Fig. 7(c). The calculated total energy fluxes are $0.028 \times 10^{-3}, 0.023$ $\times 10^{-3}$, and $0.051 \times 10^{-3} \mathrm{~J} / \mathrm{m}^{2}$. The high-frequency level reaches $90 \mathrm{~dB}$ re $1 \mu \mathrm{Pa} / \mathrm{Hz}$ at $1000 \mathrm{~Hz}$ for the strongest arrival and this is close to the background noise level.

Figures 5-7 clearly demonstrate that there is a significant multipath energy in the sound field of the seismic array. The conclusion is that the acoustic energy in the multipath must be taken into account when calculating marine mammal exposure metrics, as suggested by Madsen et al. (2006). This can only be done accurately by using propagation models to calculate the full sound field for the waveguide environment.

Sequential $2 \mathrm{~s}$ amplitude spectra for all calibrated shots are collected in Fig. 8. The high-frequency part of the spectrum $(16-21 \mathrm{kHz})$ is shown separately in Fig. 8(b), which allows better identification of the narrow spectral lines centered at $18 \mathrm{kHz}$. These represent the spectral content of the on-board echo-sounder signal. A Simrad EA500 echo sounder was part of the M/V Kondor equipment suite and emitted a $3 \mathrm{~ms}$ pulse every $12 \mathrm{~s}$ throughout the duration of the experiment. It is apparent from Fig. 8 that the highfrequency acoustic power levels from the seismic array as recorded by the EARS buoy at $739 \mathrm{~m}$ depth do not approach the levels of the echo sounder, at least for ranges below $7 \mathrm{~km}$.

Various analysis attributes are generated to quantify and characterize the acoustic output of the seismic airgun array in the ocean in addition to the time and frequency analyses already given. The results shown here can easily be compared to the other studies presented in the literature (Blackwell et al., 2004; Madsen et al., 2006). The first characteristic widely accepted in the oil industry is the maximum received pressure level, zero to peak. (Some authors report a peak-to-peak value for far-field signatures, which will not be 


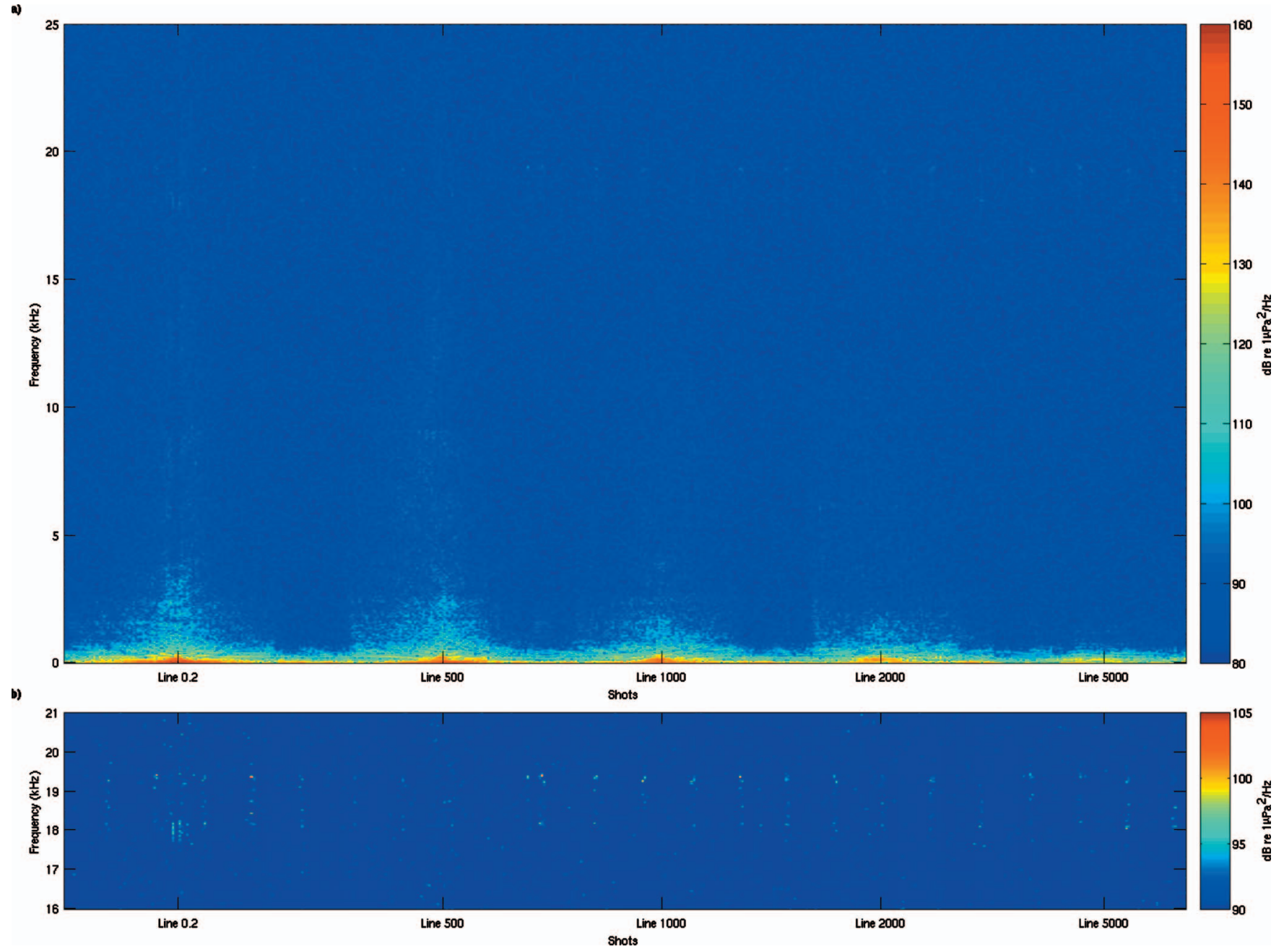

FIG. 8. (a) Sequential spectra of all calibrated shots collected over a $2 \mathrm{~s}$ rectangular window during the seismic characterization experiment from $6 \mathrm{~Hz}$ to $25 \mathrm{kHz}$. (b) High-frequency band (16-21 kHz) of the sequential spectra presented in (a). The short vertical lines centered at $18 \mathrm{kHz}$ are spectra of the $3 \mathrm{~ms}$ pulses from an $18 \mathrm{kHz}$ echo sounder on the M/V Kondor. It had a repetition rate of $12 \mathrm{~s}$.

more than $3 \mathrm{~dB}$ greater than the zero-to-peak level.) Figure 9(a) shows the maximum received pressure level for each shot collected during the experiment. The maximum level for the closest shot almost directly overhead (horizontal range of $63 \mathrm{~m}$, direct distance to the hydrophone of $736 \mathrm{~m}$, and emission angle of $5^{\circ}$ ) is $200 \mathrm{~dB}$ re $1 \mu \mathrm{Pa}$. Figure 9(b) shows the same data as a function of the horizontal range to the EARS buoy. The multivalued levels at a fixed range are due to array directionality and gun volume differences on the front versus the back of the array [see Fig. 1(a)]. The maximum received pressure levels do not gradually decrease with increasing range beyond $3 \mathrm{~km}$ for off-axis shots. They can be as high at the $5 \mathrm{~km}$ range as at the $3 \mathrm{~km}$ range due to waveguide propagation effects. These results are consistent with data recorded on sperm whales using acoustic tags during controlled exposure experiments (Madsen et al., 2006). Solid and dashed curves represent the modeled maximum levels as a function of range in the vertical $0^{\circ}$ plane aligned with the central line of the array obtained by using the parabolic equation model, RAM (Collins, 1993), and two notional source signature models: GUNDALF and NUCLEUS (Hatton, 2004; Nucleus) The details of the modeling are described in the next section. The modeled data do not reproduce all the features of measured
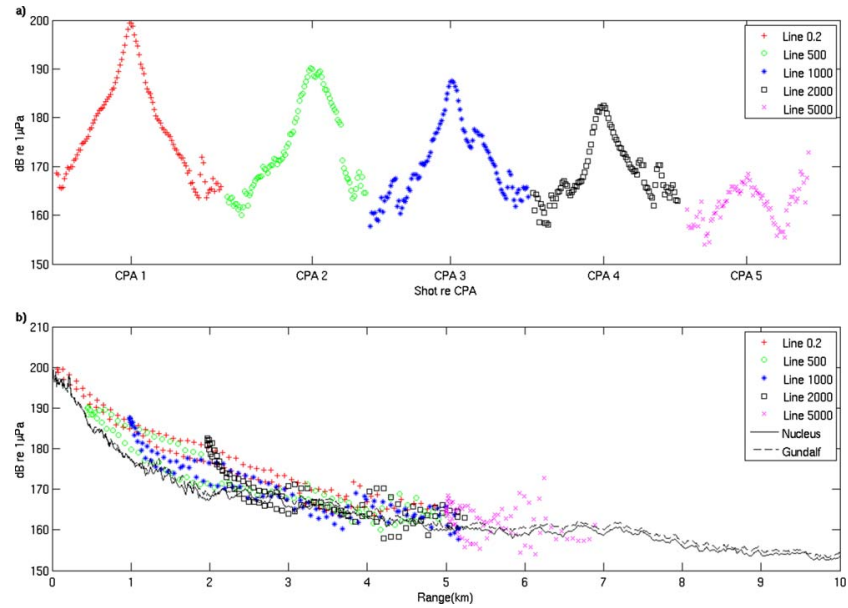

FIG. 9. (Color online) (a) Maximum received calibrated zero-to-peak sound pressure levels for each shot relative to the CPA indicated by the CPA marker on the horizontal axis for each line. (b) Maximum received zero-topeak sound pressure levels for all collected shots as a function of range. Different symbols correspond to different shot lines. Note that the maximum levels monotonically decrease only for the first $3 \mathrm{~km}$ in range. They then start increasing again for ranges larger than $3 \mathrm{~km}$, which indicates that the bottom reflected pulse dominates over the direct arrival. Solid and dashed lines are the modeled maximum received zero-to-peak sound pressure levels in the zero degree fixed vertical plane. 
data because the array directionality in different vertical planes is not taken into account due to computational time limitations. The authors are moving to parallel cluster computers to implement full three-dimensional field modeling.

Maximum levels of direct and reflected arrivals are important measures of the seismic array signal directionality and attenuation in a waveguide and provide meaningful information for seismic interpretation characterizing the reflection strength of different sub-bottom reflectors, but they cannot be used as standalone parameters to account for acoustic sensation by a marine mammal because they do not take the duration of the transient seismic pulses into account. It is suggested that most biological receivers, including marine mammals, are best modeled as energy integrators, which integrate intensity over a frequency-dependent time window (Au et al., 1997; Madsen, 2005). The integration time of $200 \mathrm{~ms}$ is chosen because it is believed to be used as an integration time by the auditory system of the endangered sperm whale. Therefore, a second attribute, SEL, is calculated over the time of each shot as

$$
\begin{aligned}
\operatorname{SEL}\left(i, t_{j}\right) & =10 \log \left\{\Delta t \sum_{m=0}^{N-1} p_{i}^{2}\left(t_{j}+m \Delta t\right)\right\} \\
& =10 \log \left\{\Delta f \sum_{k=0}^{N-1}\left|F_{i}\left(k, t_{j}\right)\right|^{2}\right\} \\
& =10 \log \left\{Z u_{i}\left(N / 2, t_{j}\right)\right\},
\end{aligned}
$$

where $i$ is the shot number in the line, $\Delta t=1.28 \times 10^{-5} \mathrm{~s}$ is the temporal sampling interval of the recorded data, $N$ $=15625$ corresponds to a $200 \mathrm{~ms}$ integration window, $p_{i}$ is the sampled recorded calibrated pressure (in micropascals) for shot $i$, and $t_{j}$ is the initial time for a $200 \mathrm{~ms}$ analysis window for every possible start time within each shot including $200 \mathrm{~ms}$ of ambient noise recording before the first seismic arrival for each shot. The maximum SEL calculated for each shot is selected to characterize that shot.

The maximum SEL for each shot in every line (sequentially) is displayed in Fig. 10(a). The maximum value for the above-mentioned closest shot is $177 \mathrm{~dB}$ re $1 \mu \mathrm{Pa}^{2}$ s. In Fig. 10(b), the maximum SEL is shown as a function of the horizontal range between the center of the array and the receiving hydrophone. Solid and dashed lines are modeled sound exposure levels in the vertical $0^{\circ}$ plane passing through the central line of the array. There are several factors that cause the maximum SEL to increase with range at ranges larger than $3 \mathrm{~km}$. The first factor is that the temporal separation between the first (direct) and the second (bottom reflected) arrivals becomes less than the integration window. The second factor is that the SEL maxima are determined by energy in the multipaths for large range off-axis shots. To support this statement, Fig. 11 shows the SEL for the entire multipath shot as a function of time for the shots shown in Figs. 5-7.

The third attribute used for the recorded data is 1/3-octave band analysis (ANSI/ASA, 2004). 1/3-octave bandwidths are reported to represent the likely lower and upper limits of auditory filters in marine mammal auditory systems for which sparse laboratory bioacoustic data are available (Richardson et al., 1995; Southall et al., 2000;
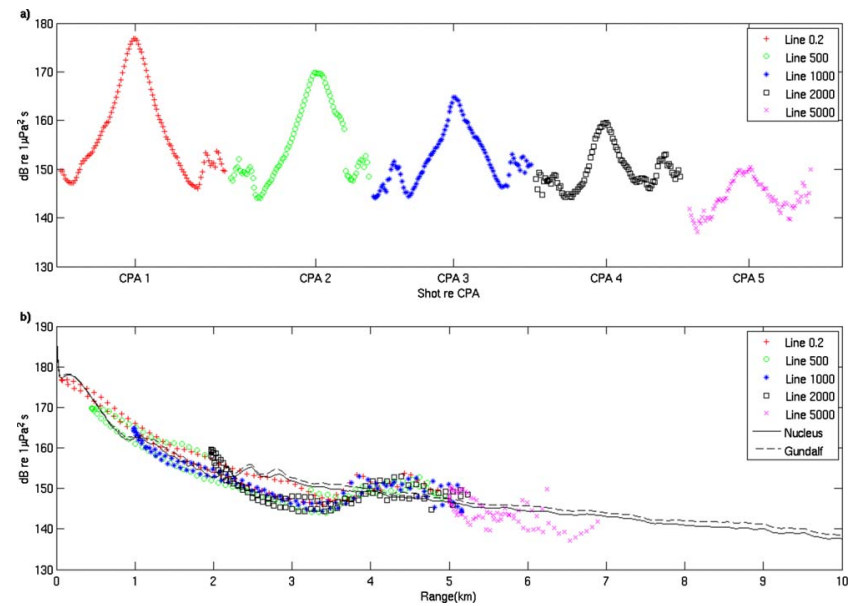

FIG. 10. (Color online) (a) Maximum sound exposure levels for a $200 \mathrm{~ms}$ sliding integration window for each shot plotted relative to the line CPA indicated by the CPA marker on the horizontal axis for each line. (b) Maximum sound exposure levels for a $200 \mathrm{~ms}$ sliding integration window for each shot shown for all shots as a function of range. Different symbols correspond to different shot lines. Solid and dashed lines are the modeled maximum sound exposure levels in the zero degree fixed vertical plane.

Southall et al., 2003). The results of 1/3-octave band analysis for all collected shots are presented in Figs. 12(a) and 12(b). The 1/3-octave band received levels are calculated for the entire received signal $(2 \mathrm{~s}$ temporal window) including all multipath arrivals received over $2 \mathrm{~s}$. Figure 12(a) shows $1 / 3$-octave band analysis of all shots sequentially plotted both within line number and by line number. Central frequencies of the bands are on the vertical axis. Band numbers 11-43 are included. Figure 12(b) shows 1/3-octave band analysis of shots within a line plotted as a function of range. The panels correspond to lines $0.2,500,1000,2000$, and 5000 .

\section{ACOUSTIC MODELING: METHODS AND RESULTS}

The seismic source acoustic energy distribution in the ocean depends not only on seismic source parameters but also on the propagation channel. Any meaningful mitigation

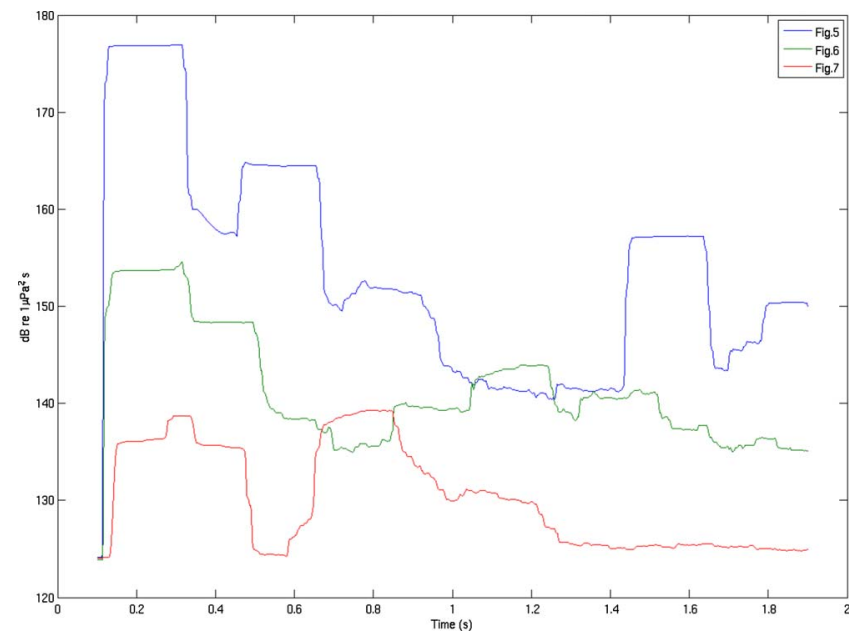

FIG. 11. (Color online) Sound exposure level vs the temporal position of the center of a $200 \mathrm{~ms}$ integration window for the entire shot (including multipath arrivals) for the three shots presented in Figs. 5-7. 
a)

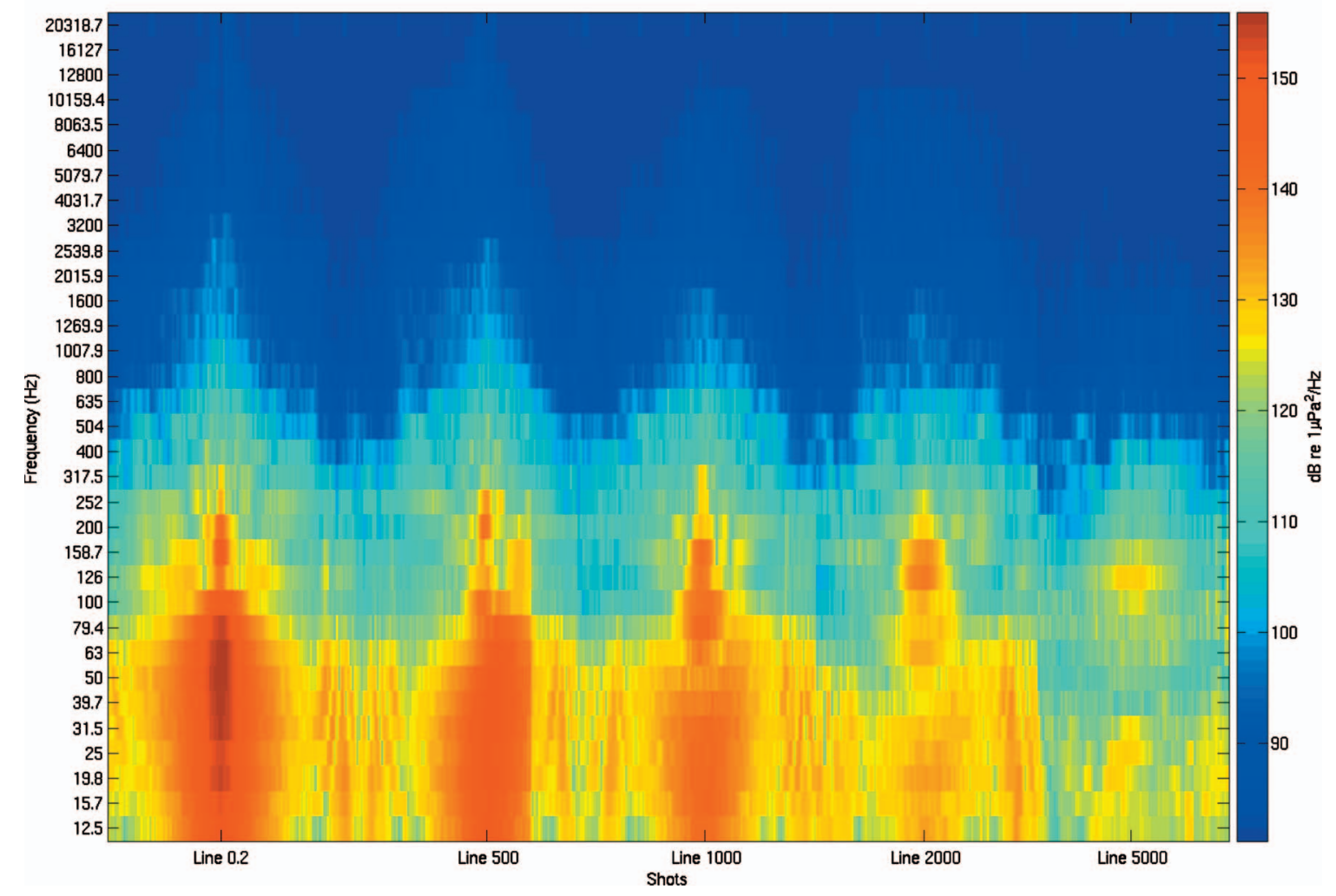

b)
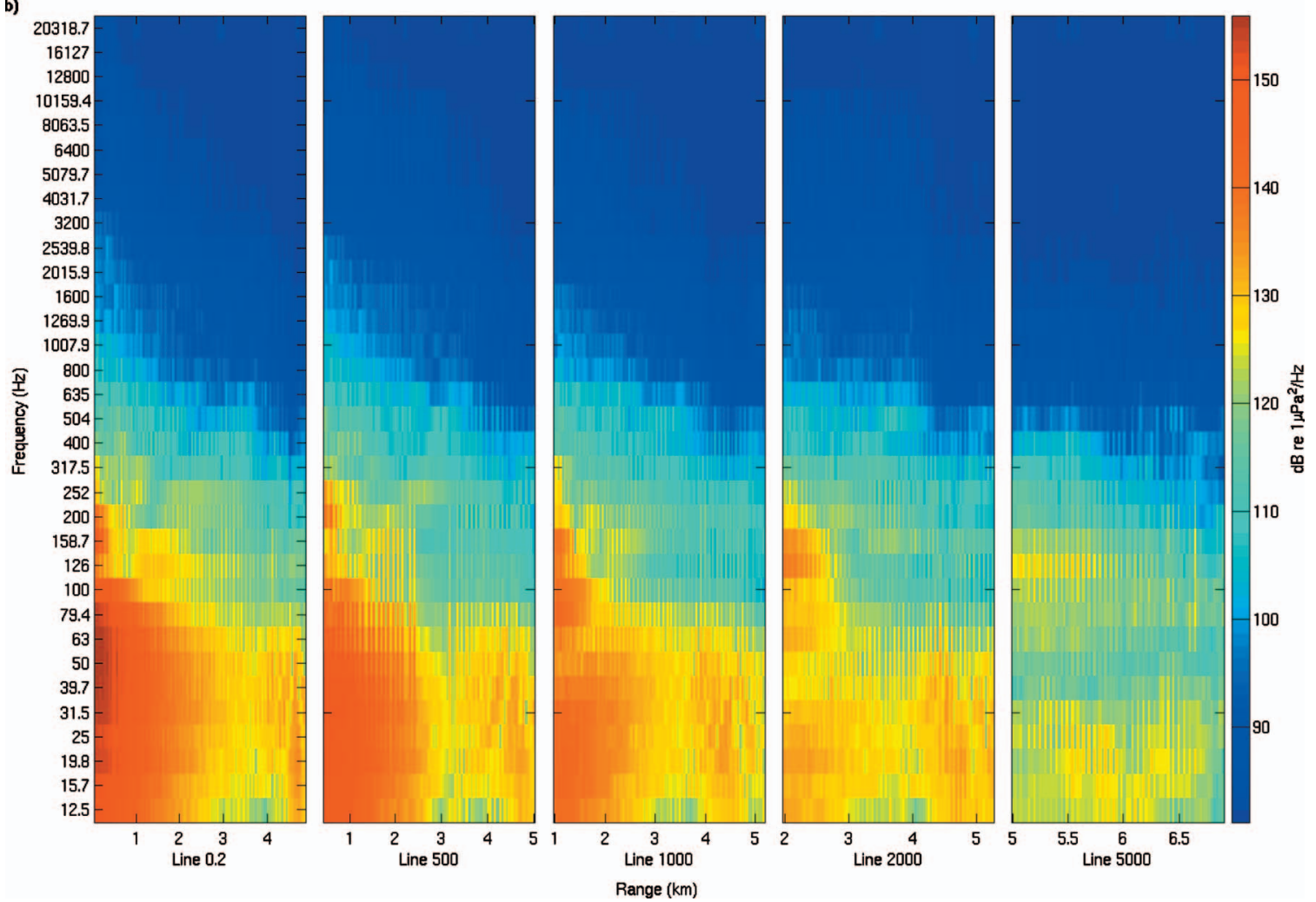

FIG. 12. (a) 1/3-octave band analysis of all shots plotted sequentially both within line number and by line number. Central frequencies of the bands are on the vertical axis and 1/3-octave bands are as defined in ANSI/ASA (2004). Band numbers 11-43 are included. (b) 1/3-octave band analysis of shots within a line plotted as a function of range. The panels correspond to lines $0.2,500,1000,2000$, and 5000 . 


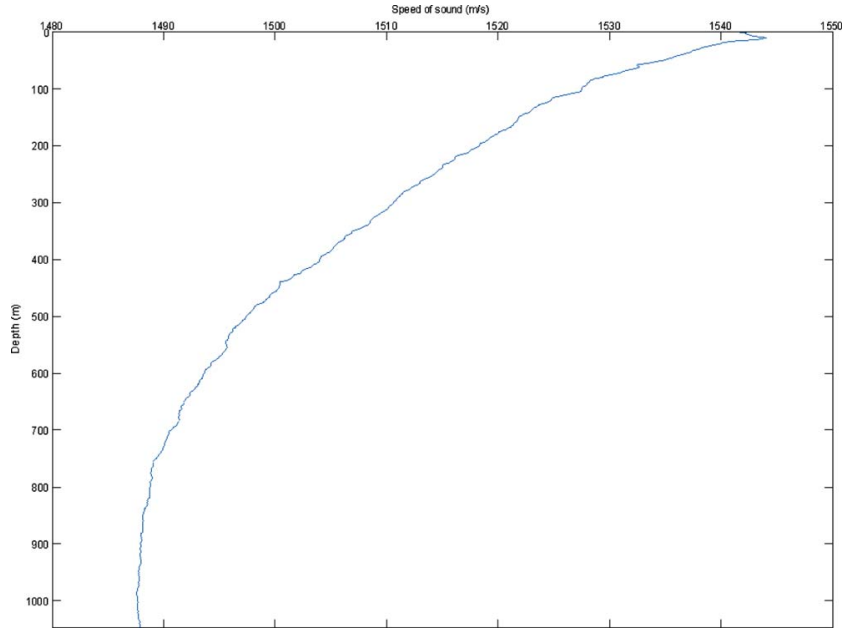

FIG. 13. (Color online) Sound speed profile in the water column during the experiment. Depth in $\mathrm{m}$ is plotted vs sound speed in $\mathrm{m} / \mathrm{s}$.

efforts will be dependent on our ability to model quantitatively the acoustic energy distribution from a given seismic array in a particular ocean waveguide. There are several standard acoustic propagation models available to model sound propagation in range-dependent ocean waveguides: RAM, KRAKEN, UMPE, SWAMP, etc. (Collins, 1993; Porter, 1995; Smith and Tappert, 1993; Sidorovskaia, 2004). However, most of the standard models are inherently two dimensional and produce the acoustic pressure distribution of a point harmonic source in the vertical plane of a source and a receiver. There are several issues that have to be addressed when using these models for quantitative modeling of the acoustic pressure distribution from a seismic array: (1) the broadband nature of the seismic pulse produced by each airgun in the array, (2) the complex temporal/angular structure of notional signatures for each airgun in the array due to bubble interactions after firing (Ziolkowski, 1970; Ziolkowski et al., 1982; Laws et al., 1990; Hatton, 2004; Nucleus), and (3) the different ranges to the receiver position for different sources in the array. The last becomes especially important in accounting for the correct relative phases of the high-frequency components at the receiver location. The quality of the calculation will be sensitive to the completeness and accuracy of the parameters describing the propagation channel and the adequacy of notional airgun source signatures to reproduce the near field of the seismic array. The sound speed profile along the propagation path for modeling was derived from expendable bathythermographs and from conductivity-temperature-depth measurements taken during the experiment (see Fig. 13). A very thin surface duct about $10 \mathrm{~m}$ thick was present during the experiment. No bottom structure information was collected during the experiment, so the bottom model for the propagation code was based on a historic database (Hamilton, 1980) and previously collected data near the experimental site (Turgut et al., 2002). The bottom model consists of three layers typically present in this area of the Gulf of Mexico: silty clay about $10 \mathrm{~m}$ deep, sand deposits up to $1 \mathrm{~km}$ deep from the bottom-water interface, and rock formations $1 \mathrm{~km}$ below the bottom-water interface.
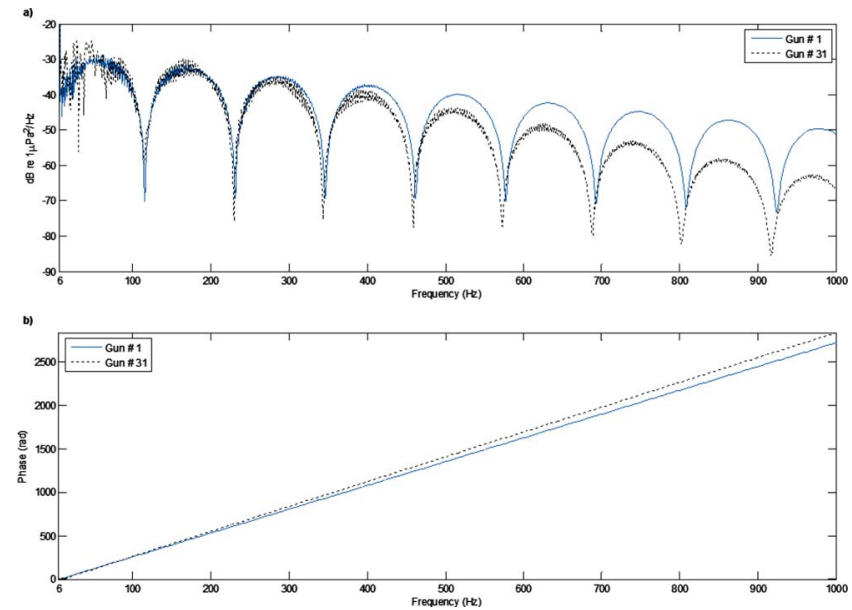

FIG. 14. (Color online) (a) Modeled waveguide transfer function levels (in $\mathrm{dB}$ re $1 \mu \mathrm{Pa}^{2} / \mathrm{Hz}$ ) for airguns 1 and 31 (airgun numbering shown in Fig. 1) for the closest approach shot 249 on line 0.2 [temporal received pressure signature is shown in Fig. 5(a)] vs frequency from 6 to $1000 \mathrm{~Hz}$. (b) The arriving phase for airguns 1 and 31 for the same shot vs frequency. The waveguide transfer functions are generated by the underwater acoustic propagation model RAM adapted to model a broadband planar array of airguns.

The calibrated pressure data are modeled using the standard parabolic equation model RAM by Collins (1993), which is upgraded to generate waveguide transfer functions for a broadband multisource array. The measured individual frequency pressure components at the receiver location, $P\left(f, r_{s}, z_{s}\right)$, are modeled in the frequency domain as

$$
P\left(f, r_{s}, z_{s}\right)=\sum_{i \text { (airguns) }} C(f) G\left(f, r_{s}, z_{s}, r_{i}, z_{i}\right) S_{i}(f),
$$

where $G\left(f, r_{s}, z_{s}, r_{i}, z_{i}\right)$ is the complex waveguide transfer function from an individual airgun to the receiver location generated by RAM, $C(f)$ is a highpass filter to cutoff RAM output below $6 \mathrm{~Hz}$ and $S_{i}(f)$ is the Fourier transform of the temporal notional signature of an individual airgun generated by two different airgun characterization models: GUNDALF and NUCLEUS. The waveguide transfer function is generated up to $1000 \mathrm{~Hz}$ with a frequency resolution of $0.5 \mathrm{~Hz}$. This frequency resolution provides a sufficiently detailed fine structure for the transfer function to account for the arrival of reflected pulses. The upper frequency is limited by the computational time required by the Parabolic Equation (PE) model to model broadband high-frequency transfer functions for a planar source. Other modeling methods for higher frequencies or a parallel processing approach will be considered to expand the frequency range of modeling in future research. Figures 14 and 15 show the transfer function levels (TFL $\left.=10 \log \left\{|G|^{2}\right\}\right)$ and arrival phases of two airguns for the closest approach shot on line 0.2 (Fig. 14) and shot 255 on line 500 (Fig. 15), which has a horizontal range of $448 \mathrm{~m}$, a direct distance to the hydrophone of $859 \mathrm{~m}$, an emission angle of $31^{\circ}$, and an azimuthal angle of $260^{\circ}$. The deep minima in Figs. 14(a) and 15(a) correspond to the interference structure due to a Lloyd's mirror effect. Analysis of this structure in the measured data allows us to correct the nominal average depth of the airguns in the array from $6 \mathrm{~m}$ recorded during the experiment to $6.7 \mathrm{~m}$ that is used in mod- 

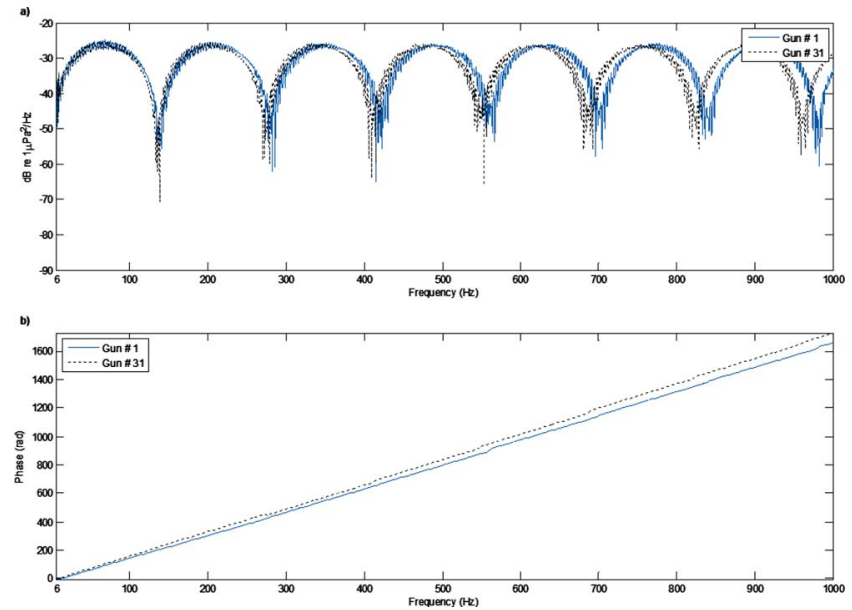

FIG. 15. (Color online) (a) Modeled waveguide transfer function levels (in $\mathrm{dB}$ re $1 \mu \mathrm{Pa}^{2} / \mathrm{Hz}$ ) for airguns 1 and 31 (airgun numbering shown in Fig. 1) for shot 255 on line 500 vs frequency from 6 to $1000 \mathrm{~Hz}$. (b) The arriving phase for airguns 1 and 31 for the same shot vs frequency. The waveguide transfer functions are generated by the underwater acoustic propagation model RAM adapted to model a broadband planar array of airguns.

eling. The fine structure of the TFL carries information about reflections from bottom layers and multipaths. The TFL and arriving phase structure indicate that a point source model is not suitable for quantitative prediction of the seismic array energy distribution in the water column.

Figure 16 shows the temporal notional signatures of selected airguns, which are generated by the NUCLEUS and GUNDALF models, for the seismic array used in the experiment. The notional signature of each airgun in the array is transformed into the frequency domain using a standard fast Fourier transform program and multiplied by RAMgenerated broadband transfer functions to model the frequency content of the calibrated shots [refer to Eq. (6)]. Figures $17(\mathrm{a})$ and $17(\mathrm{~b})$ are a comparison between experimental and simulated data with the source notional signatures generated by GUNDALF and NUCLEUS for the closest approach shot on line 0.2 (a nearly on-axis shot) and for shot 255 on
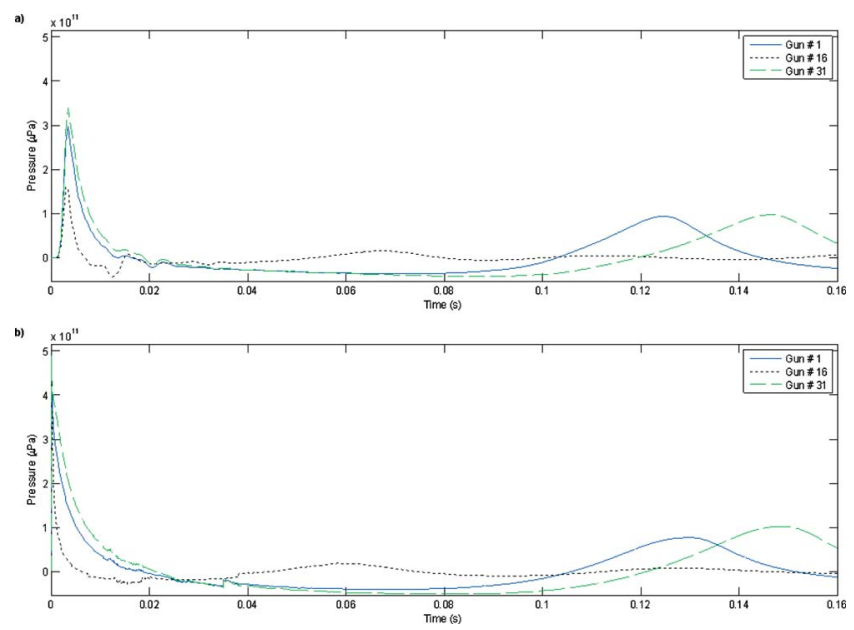

FIG. 16. (Color online) (a) Notional temporal pressure signatures (in $\mu \mathrm{Pa}$ ) for airguns 1, 16, and 31 (airgun numbering shown in Fig. 1) generated by NUCLEUS vs time in s. (b) Notional temporal pressure signatures $(\mu \mathrm{Pa})$ for the same airguns generated by GUNDALF vs time. line 500 (an off-axis shot). The NUCLEUS model has a highfrequency cutoff filter above $800 \mathrm{~Hz}$, so its modeling is only valid up to $800 \mathrm{~Hz}$. GUNDALF is designed to include the highfrequency components up to $25 \mathrm{kHz}$. There are several factors contributing to the discrepancies between experimental and simulated data. The notches in the experimental data near 500 and $750 \mathrm{~Hz}$ are most probably due to the first bottom layer reflection that is inadequately specified based on the historical database. Errors in the bottom properties have an effect on the fine structure of the modeled signal. Both airgun modeling codes show better agreement with the experimental data for on-axis shots. The notional signatures used for this calculation were generated and calibrated for on-axis use and so are not the most appropriate for off-axis use (Hatton, 2002).

The Fourier synthesis technique for digitized signals is used to model the time-domain response that was measured in the experiment and used as a starting point for the calculation of the exposure levels in the time domain. We use frequencies above $6 \mathrm{~Hz}$ for comparison with experimental data both because of the rolloff in the receiving system frequency response and because the modeled frequency components at very low frequencies are not considered fully reliable. Figures 18(a) and 18(b) show the quantitative comparison between measured and modeled signatures in the time domain for shot 255 on line 500 . We have also calculated SELs over a $200 \mathrm{~ms}$ window for the modeled received pulses in accordance with Eq. (5). Figure 18(c) shows the comparison of the modeled SEL with one calculated from the experimental data for shot 255 on line 500. The modeled and experimental sound exposure levels agree well for the direct and surface reflected arrivals and the bubble oscillation cycle. The discrepancies between modeled and experimental sound exposure levels for the times corresponding to later arrivals are due to inaccurate information about the bottom structure and for initial times are due to wraparound.

The good agreement between measured and calculated data allows us to model reliably the full three-dimensional acoustic energy distribution from the seismic array in the water column. Figure 19 shows the modeled received pressure level as a function of range, depth, and frequency for a point source placed at the center of the array. The power of the point source is equal to the total power of the array used in the experiment. Figures 20 and 21 show the modeled received pressure level as a function of range, depth, and frequency in two different vertical planes for the seismic array used in the experiment taking into account the full array geometry and spectral power components of individual array sources extracted from the notional signature frequency components. These characteristics are more meaningful to describe the broadband array radiation field in the waveguide, where array directionality is superimposed on waveguide energy channeling, than the traditional directional pattern of an array in free space. The array acoustic field structure in a waveguide is considerably different from a point source field structure in a waveguide and from the array free-space field. Generation of a series of such maps covering the full frequency band of interest and a set of vertical planes, which 

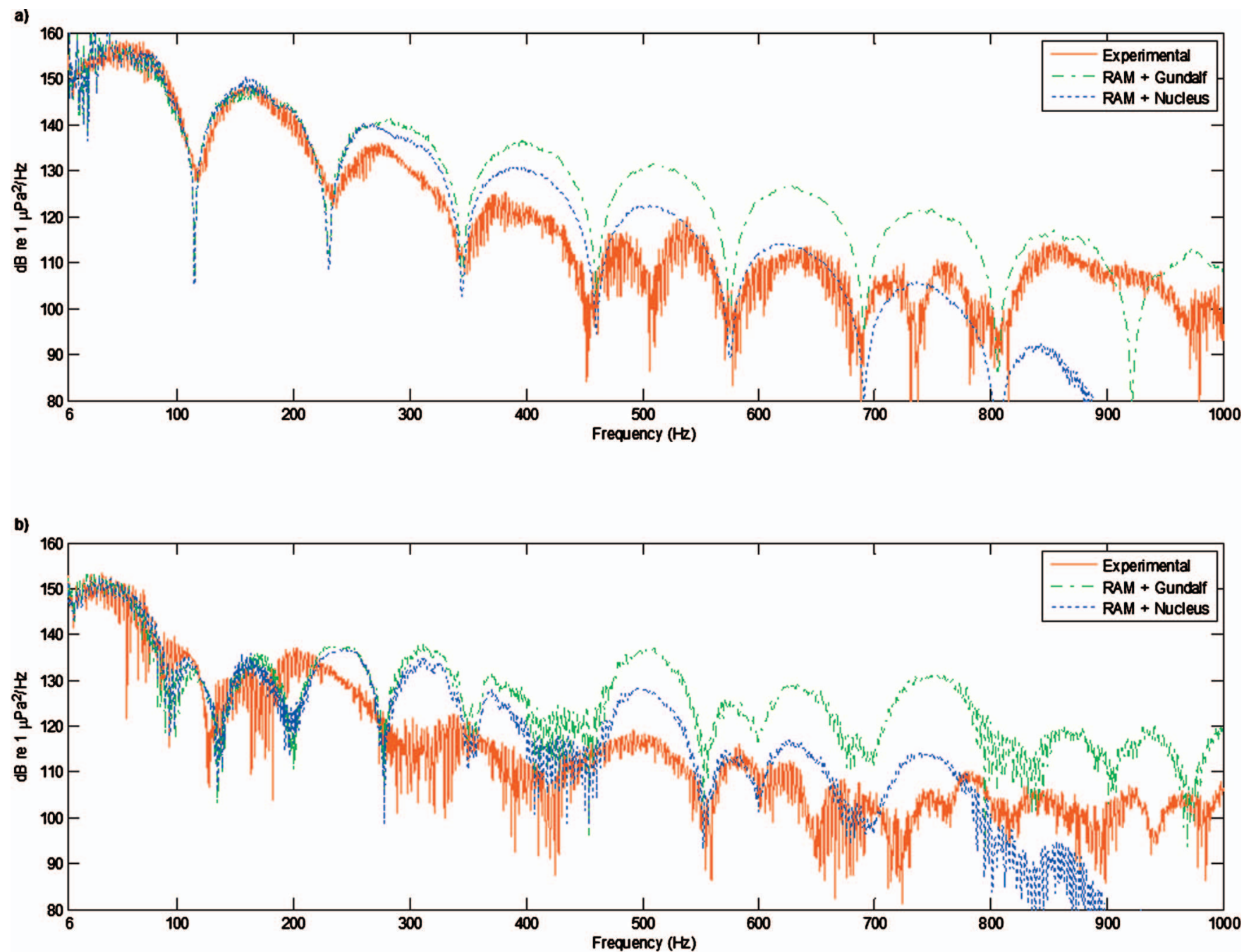

FIG. 17. Spectrum comparison (in $\mathrm{dB}$ re $1 \mu \mathrm{Pa}^{2} / \mathrm{Hz}$ ) between experimental and modeled data with the source notional signatures generated by GUNDALF and NUCLEUS vs frequency from 6 to $1000 \mathrm{~Hz}$ : (a) for the closest approach shot 249 on line 0.2 (nearly on-axis shot) and (b) for shot 255 on line 500 (off-axis shot).

allows the generation of three-dimensional SEL maps for a particular array in a particular environment, is the subject of future research.

\section{DISCUSSION AND CONCLUSIONS}

The 2003 LADC calibrated data from a typical marine seismic exploration array is a significant contribution to three-dimensional broadband seismic source characterization studies. The data set measures the absolute calibrated pressures for a wide range of angles with frequencies up to $25 \mathrm{kHz}$. This data set also provides the opportunity to test available modeling tools by quantitative comparison of measured and modeled data. However, the angular/range density of the collected data does not allow detailed testing of the reconstruction of the array directivity for a fixed range or the energy distribution in an arbitrary fixed vertical plane solely based on measured data to compare with modeled results. Additional field data should be collected for validation of the model prediction for a full three-dimensional seismic array characterization. Special attention in future experimental designs should be paid to collecting data for the close-tohorizontal propagation direction that can be critical in study-
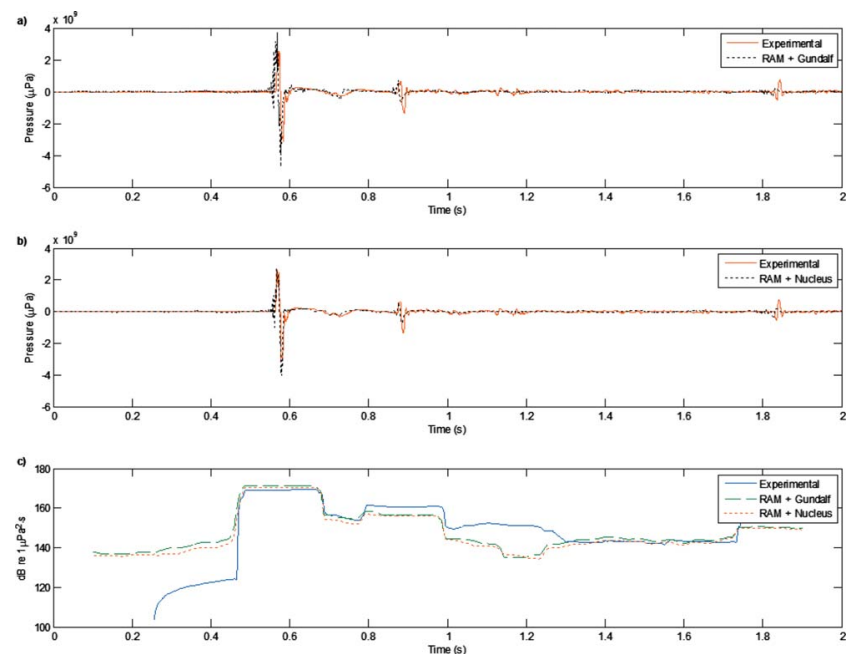

FIG. 18. (Color online) Comparison between experimental and modeled data (in $\mu \mathrm{Pa}$ ) vs time in s using frequency components from 6 to $1000 \mathrm{~Hz}$ : (a) for shot 255 on line 500 (off-axis shot) simulated with GUNDALF notional signatures, (b) for shot 255 on Line 500 (off-axis shot) simulated with NUCLEUS notional signatures, and (c) sound exposure levels calculated from experimental data and from modeled data for shot 255 . 

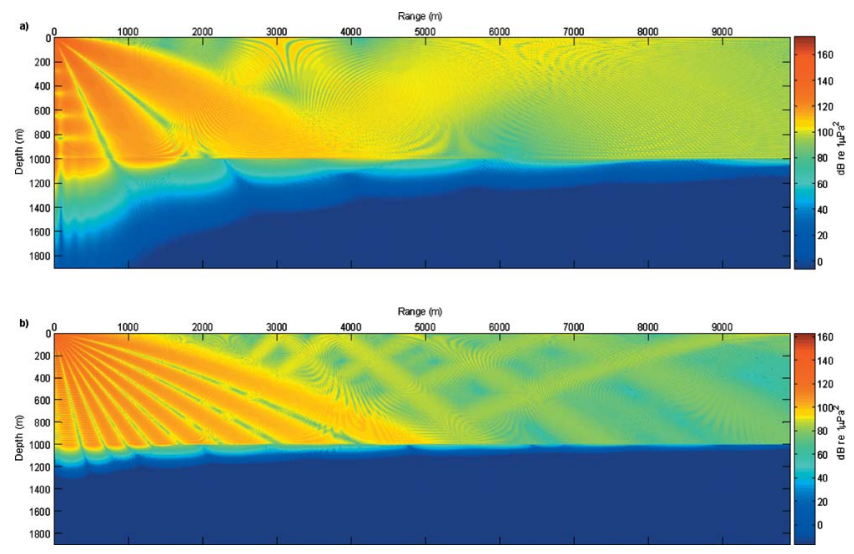

FIG. 19. (Color online) Modeled received pressure levels in $\mathrm{dB}$ re $1 \mu \mathrm{Pa}^{2}$ as a function of range from 0.01 to $10 \mathrm{~km}$ and depth from 0 to $990 \mathrm{~m}$ for a point harmonic source at depth of $6.7 \mathrm{~m}$ at (a) $300 \mathrm{~Hz}$ and (b) $1000 \mathrm{~Hz}$.

ing the issue of energy capture in a near-surface duct. Moreover, the arrival ranges should be extended to address waveguide acoustic propagation issues, such as the existence of convergence and shadow zones and surface duct effects. For example, the number of acoustic precursors formed by the surface duct will be dependent on the range (Sidorovskaia, 2004).

Propagation codes combined with notional signature models predict the broadband data reasonably well. All presented modeling results are $a b$ initio calculations with no adjustable parameters. The accuracy of prediction is limited by uncertainties in environmental information and by the accuracy of the source models. Modeling is a useful tool in the prediction of the three-dimensional acoustic energy distribution in an ocean volume of interest. It can be used to determine three-dimensional acoustic energy distribution variations due to anticipated changes in the details of future surveys including changes in ocean environmental conditions and source configuration, without necessarily conducting field experiments. Modeling allows a fairly accurate prediction of sound exposure levels for marine mammals to aid in planning future seismic surveys.
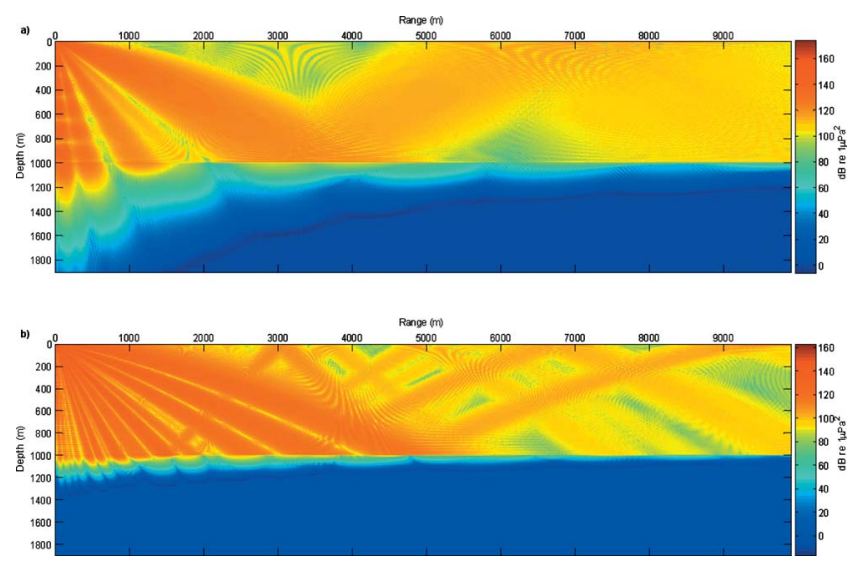

FIG. 20. (Color online) Modeled received pressure levels in $\mathrm{dB}$ re $1 \mu \mathrm{Pa}^{2}$ as a function of range from 0.01 to $10 \mathrm{~km}$ and depth from 0 to $990 \mathrm{~m}$ for the seismic array in the $0^{\circ}$-azimuthal plane (a vertical plane through the central line of the array) at (a) $300 \mathrm{~Hz}$ and (b) $1000 \mathrm{~Hz}$.
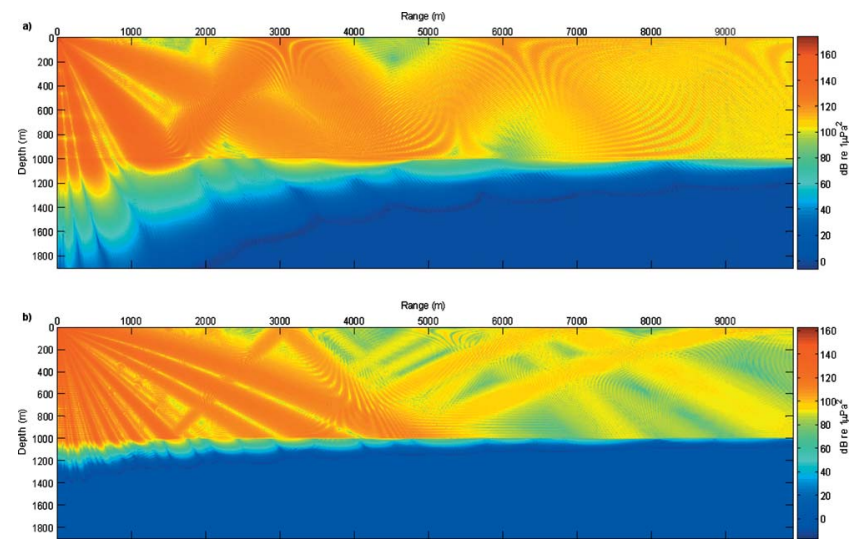

FIG. 21. (Color online) Modeled received pressure levels in $\mathrm{dB}$ re $1 \mu \mathrm{Pa}^{2}$ as a function of range from 0.01 to $10 \mathrm{~km}$ and depth from 0 to $990 \mathrm{~m}$ for the seismic array in the $90^{\circ}$-azimuthal plane (a vertical plane through the array center perpendicular to the travel direction) at (a) $300 \mathrm{~Hz}$ and (b) $1000 \mathrm{~Hz}$.

\section{ACKNOWLEDGMENTS}

This research has been funded by the Industry Research Funding Coalition through the International Association of Geophysical Contractors and the Joint Industry Project through the International Association of Oil and Gas Producers. The authors thank Phil Fontana of Veritas for supplying the source notional signatures from GUNDALF and NUCLEUS. GUNDALF is a product of Oakwood Computing, Limited, and NUCLEUS is by PGS. The authors are grateful to Phil Fontana, Les Hatton of Oakwood Computing, colleagues from the University of Southern Mississippi, particularly Grayson Rayborn and James Stephens and students Chris Walker and Ben Brack, and members of the Industry Research Funding Coalition for helpful discussions. We would like to thank the anonymous reviewers for the valuable comments that helped to improve our paper. In particular, we would like to express special thanks to one of them, whose insightful suggestions on the interpretation of experimental data, added scientific value to this publication.

ANSI/ASA (2004). "American National Standard Specification for OctaveBand and Fractional-Octave-Band Analog and Digital Filters," ANSI Report No. S1.11-2004.

$\mathrm{Au}$, W. W. L., Nachtigall, P. E., and Pawloski, J. L. (1997). "Acoustic effects of the ATOC signal $(75 \mathrm{~Hz}, 195 \mathrm{~dB})$ on dolphins and whales," J. Acoust. Soc. Am. 101, 2973-2977.

Blackwell, S. B., Lawson, J. W., and Williams, J. T. (2004). "Tolerance by ringed seals (Phoca hispida) to impact pipe-driving and construction sounds at an oil production island," J. Acoust. Soc. Am. 115, 2346-2357.

Caldwell, J., and Dragoset, W. (2000). "A brief overview of seismic air-gun arrays," The Leading Edge 19, 898-902.

Collins, M. D. (1993). "A split-step Padé solution for the parabolic equation method," J. Acoust. Soc. Am. 93, 1736-1742.

DeRuiter, S. L., Tyack, P. L., Lin, Y.-T., Newhall, A. E., Lynch, J. F., and Miller, P. J. O. (2006). "Modeling acoustic propagation of air gun array pulses recorded on tagged sperm whales (Physeter macrocephalus)," J. Acoust. Soc. Am. 120, 4100-4114.

Fricke, J. R., Davis, J. M., and Reed, D. H. (1985). "A standard quantitative calibration procedure for marine seismic sources," Geophysics 50, 15251532.

Gordon, J., Gillespie, D., Potter, J., Frantzis, A., Simmonds, M. P., Swift, R., and Thompson, D. (2004). "A review of the effects of seismic surveys on marine mammals," Mar. Technol. Soc. J. 37, 16-34.

Hamilton, E. L. (1980). "Geoacoustic modeling of the sea floor," J. Acoust. Soc. Am. 68, 1313-1340.

Hatton, L. (2002). "GUNDALF, a software package for predicting the acoustic 
signature of high pressure airguns in exploration seismology," http:// www.gundalf.com Last viewed on 8/01/07.

Hatton, L. (2004). "Incorporating marine mammal hearing sensitivity into a high-grade air gun modelling package (extended abstract)," PETEX 2004, November 2004.

Ioup, G. E., Ioup, J. W., Sidorovskaia, N. A., Walker, R. T., Kuczaj, S. A., Walker, C. D., Rayborn, G. H., Brack, B., Wright, A., Newcomb, J., and Fisher, R. (2005). "Analysis of Bottom-Moored Hydrophone Measurements of Gulf of Mexico Sperm Whale Phonations," Proceedings of 23rd Annual Gulf of Mexico Information Transfer Meeting, January 2005, pp. 109-136.

Johnston, R. C., Reed, D. H., and Desler, J. F. (1988). "Special Report of the SEG Technical Standards Committee SEG standards for specifying marine seismic energy sources," Geophysics 53, 566-575.

Labianca, F. M. (1972). "Normal modes, virtual modes, and alternative representations in the theory of surface-duct sound propagation," J. Acoust. Soc. Am. 53, 1137-1147.

Laws, R. M., Hatton, L., and Haartsen, M. W. (1990). "Computer modelling of clustered airguns," First Break 8(9), 331-338.

MacGillivray, A. O. (2006). M.S. thesis, University of Victoria.

Madsen, P. T. (2005). "Marine mammals and noise: Problems with root mean square sound pressure levels for transients," J. Acoust. Soc. Am. 117, 3952-3957.

Madsen, P. T., Johnson, M., Miller, P. J. O., Aguilar de Soto, N., Lynch, J., and Tyack, P. L. (2006). "Quantitative measures of air gun pulses recorded on sperm whales (Physeter macrocephalus) using acoustic tags during controlled exposure experiments," J. Acoust. Soc. Am. 120, 2366-2379.

Monjo, C. L., and DeFerrari, H. A. (1994). "Analysis of pulse propagation in a bottom-limited sound channel with a surface duct," J. Acoust. Soc. Am. 95, 3129-3148.

Newcomb, J., Fisher, R., Turgut, A., Field, R., Ioup, G. E., Ioup, J. W., Rayborn, G., Kuczaj, S., Caruthers, J., Goodman, R., and Sidorovskaia, N. (2002a). "Modeling and Measuring the Acoustic Environment of the Gulf of Mexico," Proceedings of the 21st Annual Gulf of Mexico Information Transfer Meeting, January 2002, pp. 509-521.

Newcomb, J., Fisher, R., Field, R., Rayborn, G., Kuczaj, S., Ioup, G. E., Ioup, J. W., and Turgut, A. (2002b). "Measurements of Ambient Noise and Sperm Whale Vocalizations in the Northern Gulf of Mexico Using Near Bottom Hydrophones," Marine Frontiers MTS/IEEE Proceedings of OCEANS'02, pp. 1365-1371.

Newcomb, J., Sanders, W., Stephens, J. M., Walker, C., Brack, B., Rayborn, G. H., Sidorovskaia, N. A., Tashmukhambetov, A. M., Ioup, G. E., Ioup, J. W., and Chapin, S. R. (2005). "Calibration and Analysis of Seismic Air gun Data from an EARS Buoy," Proceedings of 23rd Annual Gulf of
Mexico Information Transfer Meeting, January 2005, pp. 83-100.

"NUCLEUS,-Advanced tools for Survey Planning, Seismic Modelling and Feasibility Studies," http://www.pgs.com/upload/Nucleus.pdf last viewed 5/6/2008.

Porter, M. B. (1995). The KRAKEN Normal Mode Program (SACLANT Undersea Research Center, La Spezia).

Richardson, W. J., Greene, Jr., C. R., Malme, C. I., and Thomson, D. H. (1995). Marine Mammals and Noise (Academic, San Diego, CA).

Sidorovskaia, N. A. (2004). "Systematic studies of pulse propagation in ducted oceanic waveguides in normal mode representation," Eur. Phys. J.: Appl. Phys. 25, 113-131.

Sidorovskaia, N. A., and Werby, M. F. (1995). "Broad-band pulse signals and the characterization of shallow water ocean properties," Proceedings of the SPIE Conference, April 1995, pp. 97-108.

Sidorovskaia, N. A., Ioup, G. E., Ioup, J. W., Tashmukhambetov, A. M., Newcomb, J. J., Stephens, J. M., and Rayborn, G. H. (2006). "Modeling tools for 3-d air gun source characterization studies," Proceedings of the eighth European Conference on Underwater Acoustics, June 2006, edited by S. M. Jesus, and O. C. Rodriguez, pp. 95-100.

Smith, K. B., and Tappert, F. D. (1993). "UMPE: The University of Miami Parabolic Equation Model, Version 1.3," MPL Technical Memorandum No. 432.

Southall, B. L., Schusterman, R. J., and Kastak, D. (2000). "Masking in three pinnipeds: Underwater, low-frequency critical ratios," J. Acoust. Soc. Am. 103, 1322-1326.

Southall, B. L., Schusterman, R. J., and Kastak, D. (2003). "Acoustic communication ranges for northern elephant seals (Mirounga angustirostris)," Aquat. Mamm. 29.2, 202-213.

Tashmukhambetov, A. M., Sidorovskaia, N. A., Ioup, G. E., Ioup, J. W., Newcomb, J., Walker, C., Brack, B., and Rayborn, G. H. (2006). “3-D airgun source characterization and propagation modeling," SEG Technical Program Expanded Abstracts, Vol. 25, pp. 26-30.

Tolstoy, M., Diebold, J. B., Webb, S. C., Bohnenstiehl, D. R., Chapp, E., Holmes, R. C., and Rawson, M. (2004). "Broadband calibration of R/V Ewing seismic sources," Geophys. Res. Lett. 31, L14310.

Turgut, A., McCord, M., Newcomb, J., and Fisher, R. (2002). "Chirp sonar sediment characterization at the northern Gulf of Mexico Littoral Acoustic Demonstration Center experimental site," Proceedings of the Oceans '02 MTS/IEEE, Vol. 4, pp. 2248-2252.

Ziolkowski, A. (1970). "A method for calculating the output pressure waveform from an air gun,” Geophys. J. R. Astron. Soc. 21, 137-161.

Ziolkowski, A., Parkes, G., Hatton, L., and Haugland, T. (1982). "The signature of an air gun array: Computation from near-field measurements including interactions," Geophysics 47, 1413-1421. 